\title{
Inheritance of DNA methylation differences in the mangrove Rhizophora mangle
}

\author{
Jeannie Mounger ${ }^{1}$ () । M. Teresa Boquete ${ }^{1,2}$ (1) | Marc W. Schmid ${ }^{3}$ () ।

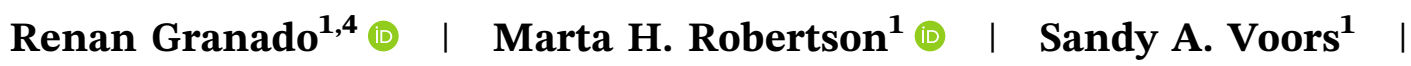 \\ Kristen L. Langanke $^{1}$ | Mariano Alvarez ${ }^{1,5}$ ( ) | Cornelis A. M. Wagemaker \\ Aaron W. Schrey ${ }^{7}$ (1) । Gordon A. Fox ${ }^{1}$ () | David B. Lewis ${ }^{1}$ (ㄷ) । \\ Catarina Fonseca Lira ${ }^{4}$ (i) | Christina L. Richards ${ }^{1,8}$
}

\author{
${ }^{1}$ Department of Integrative Biology, University of South Florida, Tampa, Florida, USA \\ ${ }^{2}$ Department of Evolutionary Ecology, CSIC, Estación Biológica de Doñana, Sevilla, Spain \\ ${ }^{3}$ MWSchmid GmbH, Zurich, Switzerland \\ ${ }^{4}$ Diretoria de Pesquisas, Instituto de Pesquisas Jardim Botânico do Rio de Janeiro, Rio de Janeiro/RJ, Brazil \\ ${ }^{5}$ Avalo, Durham, NC, USA \\ ${ }^{6}$ Department of Experimental Plant Ecology, Radboud University, Nijmegen, The Netherlands \\ ${ }^{7}$ Department of Biology, Georgia Southern University, Armstrong Campus, Savannah, Georgia, USA \\ ${ }^{8}$ Plant Evolutionary Ecology, University of Tübingen, Institute of Evolution \& Ecology, Tübingen, Germany
}

\section{Correspondence}

Christina L. Richards, Department of Integrative Biology, University of South

Florida, 4202 E. Fowler Ave, Tampa,

FL 33620, USA.

Email: clr@usf.edu

\section{Funding information}

Ministerio de Ciencia e Innovación, Grant/Award Number: Juan de La Cierva incorporación IJC2018- 035018-I; Bundesministerium für Bildung und Forschung, Grant/Award Number: 306055; National Science Foundation, Grant/Award Numbers: DEB-1419960, IOS-1556820; Coordenação de Aperfeiçoamento de Pessoal de Nível Superior, Grant/Award Number: 072/ 2014; H2020 Marie Sklodowska-Curie Actions, Grant/Award Number: 704141

\begin{abstract}
The capacity to respond to environmental challenges ultimately relies on phenotypic variation which manifests from complex interactions of genetic and nongenetic mechanisms through development. While we know something about genetic variation and structure of many species of conservation importance, we know very little about the nongenetic contributions to variation. Rhizophora mangle is a foundation species that occurs in coastal estuarine habitats throughout the neotropics where it provides critical ecosystem functions and is potentially threatened by anthropogenic environmental changes. Several studies have documented landscape-level patterns of genetic variation in this species, but we know virtually nothing about the inheritance of nongenetic variation. To assess one type of nongenetic variation, we examined the patterns of DNA sequence and DNA methylation in maternal plants and offspring from natural populations of $R$. mangle from the Gulf Coast of Florida. We used a reduced representation bisulfite
\end{abstract}

Jeannie Mounger, M. TeresaBoquete, and Marc W. Schmid shared first author.

This is an open access article under the terms of the Creative Commons Attribution License, which permits use, distribution and reproduction in any medium, provided the original work is properly cited.

(c) 2021 The Authors. Evolution \& Development published by Wiley Periodicals LLC. 
sequencing approach (epi-genotyping by sequencing; epiGBS) to address the following questions: (a) What are the levels of genetic and epigenetic diversity in natural populations of $R$. mangle? (b) How are genetic and epigenetic variation structured within and among populations? (c) How faithfully is epigenetic variation inherited? We found low genetic diversity but high epigenetic diversity from natural populations of maternal plants in the field. In addition, a large portion (up to $25 \%$ ) of epigenetic differences among offspring grown in common garden was explained by maternal family. Therefore, epigenetic variation could be an important source of response to challenging environments in the genetically depauperate populations of this foundation species.

\section{K E Y W O R D S}

coastal ecosystems, conservation genomics, epigenetic inheritance, foundation species, mangrove

\section{1 | INTRODUCTION}

Preserving the ability of populations to respond to environmental challenges is critical to conservation efforts. This ability ultimately depends on phenotypic variation (Björklund et al., 2009; Henn et al., 2018; Norberg et al., 2001). Conserving genetic variation has been championed by numerous researchers studying conservation in recent decades to ultimately preserve these phenotypic options (Allendorf et al., 2012). However, the focus on genetic variation must be interpreted with caution (Hufford \& Mazer, 2003) considering the misplaced emphasis on the concept that only variation in DNA sequence matters (Bonduriansky \& Day, 2018; Keller, 2002, 2014; Sultan, 2015). In fact, Sultan (2015) argued that as modern biologists our task is to restore the context dependence of gene expression and trait variation. This task has become particularly relevant in the context of anthropogenic alterations to natural ecosystems. In the framework of re-evaluating the mapping of genotype to phenotype (Keller, 2014; Pigliucci, 2010), we can now use the concepts of Evo-Devo to explore phenotypic plasticity and genetic and nongenetic structure within populations, as well as examine how these processes are impacted by climate change (Campbell et al., 2017).

Natural epigenetic variation (e.g., alterations to DNA methylation, small RNAs, and chromatin remodeling) has been associated with phenotypic and functional diversity in plants, emerging both as a molecular-level mechanism underlying phenotypic plasticity and as a potentially important nongenetic source of heritable variation (Balao et al., 2018; Banta \& Richards, 2018;
Cortijo et al., 2014; Medrano et al., 2014; Zhang et al., 2018). There is increasing evidence that suggests that environmentally-induced epigenetic variation can be heritable, particularly in plants (e.g., Herrera et al., 2017; Richards et al., 2012; Verhoeven et al., 2010) but this contention is not universally supported (reviewed in Richards \& Pigliucci, 2020). This source of variation may be imperative for sessile organisms, and for organisms with limited dispersal ability, as they cope with a broad range of environmental conditions without the ability to migrate away from stressors (Balao et al., 2018; Dodd \& Douhovnikoff, 2016). Further, rapid phenotypic alterations mediated by epigenetic mechanisms may be especially important for persistence in dynamic ecosystems that face significant natural environmental variation as well as anthropogenic impacts, such as those in coastal and alpine regions (Burggren, 2016; Jueterbock et al., 2020; Neinavaie et al., 2021; Nicotra et al., 2015).

Much of what is presently known about the functionality of epigenetic variation predominantly comes from studies of model organisms (Balao et al., 2018; Niederhuth \& Schmitz, 2017; Richards et al., 2017). For instance, epigenetic differences in Arabidopsis thaliana have been linked to heritability in flowering time and primary root length (Cortijo et al., 2014), response to temperature (Kawakatsu et al., 2016), and biotic stressors (Dowen et al., 2012) reviewed in Zogli and Libault (2017). Additionally, inheritance of environmentally induced epigenetic variation has been observed in A. thaliana (Blevins et al., 2014; Lang-Mladek et al., 2010), as well as in several crop species (Bilichak et al., 2015; De Kort et al., 2020; Li et al., 2014) and dandelions (Verhoeven et al., 2010). However, our understanding of how 
epigenetic variation behaves in a variety of species and ecological contexts is growing (Mounger et al., 2021; Neinavaie et al., 2021; Richards \& Pigliucci, 2020; Richards et al., 2017). Common garden studies of non-model plant species have elucidated changes in DNA methylation that are associated with community composition (van Moorsel et al., 2019), responses to temperature and nutrient stress (Nicotra et al., 2015; Verhoeven et al., 2010), and inheritance of induced responses (aka transgenerational plasticity; Herman \& Sultan, 2016; Puy, Carmona, et al., 2021; Puy, de Bello, et al., 2021; Shi et al., 2018). Moreover, methylation differences in natural plant populations have been associated with response to habitat (Foust et al., 2016; Gáspár et al., 2019; Jueterbock et al., 2020; Lira-Medeiros et al., 2010; Schulz et al., 2014; Xie et al., 2015), biotic interactions (e.g., herbivory; Herrera \& Bazaga, 2011); reviewed in Alonso et al. (2019), hybridization and allopolyploidization (Mounger et al., 2021; Salmon et al., 2005; Sehrish et al., 2014) and domestication (Chen et al., 2020). However, other studies have shown that epigenetic changes could be explained by single genetic mutations, and several authors have argued that epigenetic variation is largely explained by genetic variation (Becker et al., 2011; Dubin et al., 2015; Sasaki et al., 2019).

Understanding the mechanisms of response in foundation species has become increasingly important for conservation and management strategies. Work in foundation species supports the idea that these species disproportionately contribute to maintaining habitat integrity and ecosystem resilience (Ellison, 2019; Keith et al., 2017; Bertness 2020; Qiao et al., 2021). In coastal ecosystems, foundation species must cope with several anthropogenic impacts of habitat destruction and global climate change (Alongi, 2008; Osland et al., 2013; Osland, Day, et al., 2017; Osland, Griffith, et al., 2017). Worldwide, mangrove forests perform significant ecosystem services including buffering storm surges and tidal wave action, reducing erosion, sequestering an estimated $34.4 \mathrm{Tg}$ of carbon per year (Mcleod et al., 2011), and providing habitat for economically important marine fauna (Alongi, 2008). These forests also play important roles in nutrient and sediment dynamics that are integral to the ecosystem processes of several marine systems, notably coral reefs and seagrass flats (Alongi, 2008; Polidoro et al., 2010). Despite their importance, the distribution and persistence of mangrove tree species are threatened by historic and current land-use change as well as by pollution from agriculture and urban runoff, sewage effluents, hazardous materials spills, and other contaminants from human activities (Ellison et al., 2015). Evidence has suggested that populations of many mangrove species have moved along the intertidal zone and poleward at pace with changes in sea level, reduced incidence of winter frost, and a variety of other abiotic conditions (Alongi, 2008; Osland, Day, et al., 2017). The mechanisms that allow for this migration are not well understood (Osland et al., 2013; Osland, Griffith, et al., 2017) and coastal development poses a significant barrier to the species' ability to colonize landward (Polidoro et al., 2010; Schuerch et al., 2018) (reviewed in Godoy \& de Lacerda, 2015).

To date, broad surveys of genetic diversity across the expansive ranges of mangrove species are lacking, and virtually no studies have directly addressed the importance of nongenetic variation for the persistence of coastal plant species (but see Foust et al., 2016; LiraMedeiros et al., 2010; Robertson et al., 2017; Spens \& Douhovnikoff, 2016). Genetic variation in the red mangrove, Rhizophora mangle L., has been investigated in various geographic regions to assess patterns of evolution (Duke et al., 2002), hybridization and introgression (Cerón-Souza et al., 2010), genetic population, and subpopulation structure (Albrecht et al., 2013; ArbeláezCortes et al., 2007; Bruschi et al., 2014; Cerón-Souza et al., 2010; Chablé Iuit et al., 2020), and range expansion in response to climate change (Kennedy et al., 2017; Sandoval-Castro et al., 2012). R. mangle populations vary tremendously in genetic variation across their range. For example, populations along the Pacific Coast of the Americas have greater genetic diversity than those sampled elsewhere within their range (ArbeláezCortes et al., 2007; Bruschi et al., 2014; Cerón-Souza et al., 2012). Other studies also suggest that $R$. mangle populations are not well connected through gene flow (i.e., panmictic; Pil et al., 2011)). Instead, they tend to form somewhat isolated groups, particularly at range ends and in areas of limited tidal flow (Kennedy et al., 2017; Sandoval-Castro et al., 2012).

In this study, we used the reduced representation bisulfite sequencing approach epigenotyping by sequencing (epiGBS; van Gurp et al., 2016)) to measure genetic and DNA methylation differentiation among red mangrove populations near the northern limit of this species in the Tampa Bay region. We took advantage of the unusual biology of $R$. mangle that allows for collecting viviparous propagules that are still attached to the maternal plant. From six populations we collected leaves from maternal trees and their offspring propagules to answer the following questions: (a) What are the levels of genetic and epigenetic diversity in natural populations of R. mangle? (b) Are genetic and epigenetic variation structured among populations of this species in the wild? (c) To what extent does epigenetic variation in the offspring correlate with the maternal plants? 


\section{2 | MATERIALS AND METHODS}

\section{1 | Study species}

The red mangrove, $R$. mangle L. 1753 (Malpighiales, Rhizophoraceae), is an estuarine tree species present along the tropical and subtropical coasts of the Americas, eastern Africa, Bermuda, and a handful of outlying islands in the South Pacific (DeYoe et al., 2020; Proffitt \& Travis, 2014; Tomlinson, 2016). Rhizophora mangle typically grows in the intertidal regions of sheltered coastlines, but can also be found in estuaries, tidal creeks, and occasionally along the edges of hypersaline salt pans (DeYoe et al., 2020; Duke et al., 2002). It is a dominant mangrove species across its range, including along peninsular Florida (DeYoe et al., 2020). Like other mangrove species, $R$. mangle functions as a foundation species by altering environmental conditions, providing nursery grounds for numerous fish species, and serving as a crucial primary producer within tropical and subtropical estuarine environments (Ellison, 2019; Ellison et al., 2005; Proffitt \& Travis, 2005).

$R$. mangle is a monoecious, self-compatible species (Nadia \& Machado, 2014). Pollination in this species is mediated by both insects and wind (ambophilous pollen dispersal), which has been shown to effectively promote outcrossing and long-distance gene flow, but these outcrossing events are thought to be rare (Cerón-Souza et al., 2012). $R$. mangle produces viviparous propagules that mature for up to 6 months on maternal trees to lengths of 15-20 cm (DeYoe et al., 2020; Goldberg \& Heine, 2017). These propagules have considerable longevity at sea, surviving up to 3-4 months in the water column allowing a great potential for long-distance dispersal through ocean current transportation (Duke et al., 2002; Rabinowitz, 1978). However, propagules frequently recruit either directly underneath or within short distances of maternal trees (Goldberg \& Heine, 2017; Sengupta et al., 2005; Sousa et al., 2007). Maximum tidal action via king tides and major weather events may be required to move propagules significant distances (Goldberg \& Heine, 2017).

\section{2 | Field sampling}

We sampled six populations of $R$. mangle between June 9 and June 26, 2015, in the west coast of central Florida (USA) within the following county and state parks: Anclote Key Preserve State Park (AC), Fort De Soto Park (FD), Honeymoon Island State Park (HI), Upper Tampa Bay Conservation Park (UTB), Weedon Island Preserve (WI), and Werner-Boyce Salt Springs State Park (WB)
(Figure 1). At each population, we collected leaf tissue and 20 propagules directly from each of 10 maternal trees separated by at least $10 \mathrm{~m}$ from each other to maximize the range of genetic variation sampled within each population (Albrecht et al., 2013). With this design, propagules from each maternal tree were at least halfsiblings but they could be more closely related due to the reported high selfing rate of $R$. mangle in the study area (Proffitt \& Travis, 2005). We maintained leaf tissue of maternal trees on ice until transported to the Richards laboratory at the University of South Florida and then stored samples at $-80^{\circ} \mathrm{C}(N=60)$. We refrigerated the propagules at $4^{\circ} \mathrm{C}$ for up to 14 days until we planted them in the greenhouse at the University of South Florida Botanical Gardens. In the greenhouse, propagules from four of the maternal trees at $\mathrm{AC}$ and nine of the maternal trees at FD failed to establish, so we returned to sample propagules and maternal tissue from 8 new maternal trees at FD on August 12 and 29, and from the same original maternal trees at AC on October 17.

We planted propagules in $0.5 \mathrm{~L}$ pots with a $50: 50$ mixture of sand and peat soil and grew them for 9 months in the greenhouse at $18-29^{\circ} \mathrm{C}$ as part of a large common garden experiment designed to assess propagule response to salinity ( $15 \mathrm{ppt}$ and $45 \mathrm{ppt}$ reflecting the

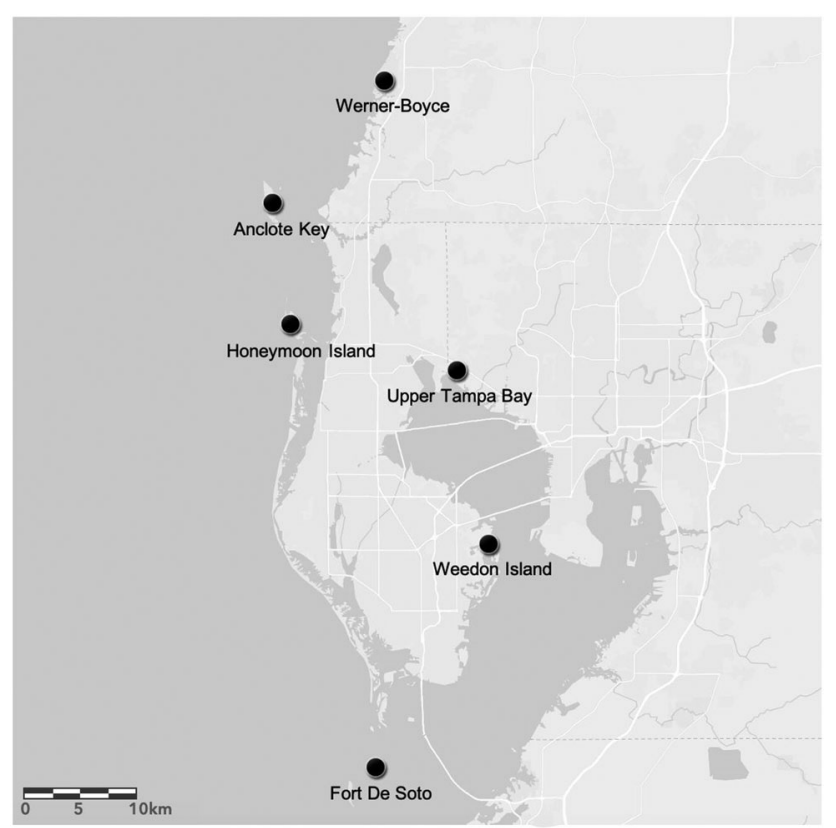

FI G URE 1 Map of six collection sites (aka populations) within the greater Tampa Bay region (FL, USA) generated in ArcGIS. We collected Rhizophora mangle leaves and propagules from ten maternal trees in Werner-Boyce Salt Springs State Park (WB), Anclote Key Preserve State Park (AC), Honeymoon Island State Park (HI), Upper Tampa Bay Conservation Park (UTB), Weedon Island Preserve (WI), and Fort De Soto Park (FD) 
range of salinity measured in the field populations) and nitrogen $(\mathrm{N})$ (no $\mathrm{N}$ amendment and high $\mathrm{N}$, amended at approximately $3 \mathrm{mg} \mathrm{N}$ per pot each week, which is equivalent to a rate of $75 \mathrm{~kg} \mathrm{~N}$ per hectare per year; Langanke, 2017). The experiment was set up in five spatial blocks. Within each block we randomized the position of plants such that each block had one replicate of each family for each treatment combination (i.e., a full factorial randomized complete block design with $N=6$ populations $\times 10$ maternal families $\times 4$ treatment combinations $\times 5$ blocks $\times \sim 1$ replicate $/$ block $=1150$ plants; Langanke, 2017; Richards et al., 2021).

We watered all plants daily with tap water until propagules were planted and established for several weeks. In mid-October, we started applying treatments twice per week. Replicates of some families were not represented in all five blocks due to limitations in the number of viable propagules. We sampled one block of plants per day between 2 and 7 May 2016, storing leaf tissue from each plant in paper envelopes, which we dried in large glass containers with silica gel desiccant beads $(N=841$ plants with leaves at the end of the experiment, ranging from 97 to 183 offspring per population). For the current study, we wanted to assess inheritance of epigenetic variation. Since epigenetic variation can be induced by environmental variation, we only used plants from the low salinity, no nitrogen amendment treatment for the epigenetic analysis $(N=158)$.

\section{3 | Laboratory methods}

For genetic and epigenetic analyses, we isolated total genomic DNA from a total of 247 samples, including 60 maternal trees from the field and 187 offspring grown in the greenhouse. The 187 individuals represented 46 maternal families across the six populations (5-10 families per population). We increased replication of some families for genetic (not epigenetic) diversity analyses with 29 plants that had received either high salt or high nitrogen treatments. By population, in the final group of samples that made it through the filtering process these 29 samples included AC ( 3 of 10 individuals), FD (5/47), HI (3/19), UTB (8/49), WB (4/24), WI (6/38) (Table S1).

To prepare the epigenotyping-by-sequencing (epiGBS) libraries, we disrupted approximately $80 \mathrm{mg}$ of leaf tissue using stainless steel beads in a Qiagen TissueLyser II. Then, we extracted the DNA using the Qiagen Dneasy Plant Mini Kit following the manufacturer instructions with slight modifications that included an extended lysis step, a post-extraction clean-up with Buffer AW2, and elution in molecular grade water. The final concentration of DNA was quantified using the Qubit 3.0 Fluorometric dsDNA BR assay kit (Life Technologies).

We prepared libraries for epiGBS following the methods outlined in van Gurp et al. (2016). In brief, we digested $400 \mathrm{ng}$ of genomic DNA from each sample with the methylation-sensitive restriction enzyme PstI, and ligated methylated, non-phosphorylated barcoded adapters to the resulting fragments. The barcoded adaptors were designed so that we can identify forward ("Watson") and reverse ("Crick") strands for each fragment within each individual. Having the strand information allows for differentiating between $\mathrm{C} / \mathrm{T}$ polymorphisms and methylation polymorphisms because we can recreate when unmethylated cytosines were present in either strand before bisulfite treatment (for details see van Gurp et al., 2016).

We concentrated the libraries (NucleoSpin ${ }^{\mathrm{TM}} \mathrm{Gel}$ and PCR Clean-up Kit), and size selected the fragments using $0.8 \times$ SPRI beads (Agencourt AMPure XP; Beckman Coulter). We performed nick translation, bisulfite converted the fragments (EZ Lightning methylation kit; Zymo Research), and performed polymerase chain reaction amplification with the KAPA HIFI Uracil+ Hotstart Ready Mix (Roche). Finally, we quantified the libraries using the Qubit dsDNA assay kit, pooled them with equimolar concentrations (each sequenced library consisted of 96 multiplexed samples), and assessed their quality by analyzing $1 \mu \mathrm{l}$ on a High Sensitivity DNA chip using an Agilent 2100 Bioanalyzer. We prepared libraries and sequenced paired-end reads of the 60 maternal plant samples and 36 randomly chosen offspring at the University of Florida Interdisciplinary Center for Biotechnology Research on one lane of the Illumina HiSeq. $3000(2 \times 150$ bp $)$ in February 2017. In August 2017, we prepared separate libraries for an additional 151 offspring and sequenced them at Novogene (HK) Company Limited in Hong Kong on two lanes of the Illumina HiSeq $\mathrm{X}$-Ten System $(2 \times 150 \mathrm{bp})$ : one lane contained 96 offspring samples, a second lane held 55 offspring samples along with 40 samples of another species prepared with the same protocol for another study (Ceratodon purpureus; Boquete et al., unpublished).

\section{4 | Data processing}

We processed the raw sequencing files using the pipeline provided by van Gurp et al. (2016) as in van Moorsel et al. (2019), available on https://github. Com/ thomasvangurp/epiGBS, with a bug-fix modification (i.e., described in Gawehns et al., 2020); https://github. com/MWSchmid/epiGBS_Nov_2017_fixed). Briefly, we 
demultiplexed, quality trimmed sequencing reads, and removed the barcode sequences, then used the processed reads for de novo reference construction. We mapped the reads to the de novo reference and called strand-specific single nucleotide polymorphisms (SNPs) and methylation polymorphisms (SMPs). De novo reference sequences were annotated with DIAMOND (protein coding genes; NCBI nonredundant proteins as reference; version 0.8.22; Buchfink et al., 2015) and RepeatMasker (transposons and repeats; Embryophyta as reference species collection; version 4.0.6; Smit et al., 2013-2015)). This annotation was used to classify the genetic variants (SNPs) and epigenetic variants (SMPs) into the different genomic features including genes, repeats, and transposons.

SNPs and SMPs were filtered to include only loci with a minimum coverage of five (i.e., five sequencing reads mapping to each locus) and a maximum coverage of 10,000 within each individual and across at least five individuals with a maximum coverage of 10,000 in at least five samples per population and sample type (maternal trees and offspring). First, samples with read coverage $<5$ and $>10,000$ were considered missing values. Then, we removed SNPs and SMPs that were not present in at least five individuals per population and sample type. Second, samples for which fewer than $60 \%$ of the SNP or SMP sites passed this filter were removed. This removed 59 samples from the original design, one maternal tree from FD, and 58 offspring spread across populations. The final design includes 59 maternal trees and 129 offspring (between 7 and 39 offspring per population from 3 to 10 maternal trees per population; Table S1). Third, we repeated the first filtering step using the original SNP and SMP datasets and the final design which resulted in 48,964 SMPs and 62,944 SNPs present in at least $51 \%$ of the samples, and evenly spread across populations and sample types.

\section{5 | Data analysis}

We separated each of the filtered SNP and SMP datasets into two distinct datasets comprising maternal trees and offspring respectively. Thus, all analyses were performed on the maternal trees and on the offspring datasets separately. We did not directly compare both datasets due to the fact that the resulting filtered datasets from the maternal trees and the offspring did not overlap for the most part, reflecting technical differences in sample storage between the maternal trees and the offspring (i.e., frozen vs. dry), and that their libraries were prepared and sequenced at different times. All the analyses were performed in $\mathrm{R}$ version 3.5.1 ( $\mathrm{R}$ Core Team, 2020).
All statistical analyses were done in the complete maternal tree data set from the final design $(N=59$ maternal trees from six populations $\times 9-10$ maternal trees per population). For the offspring data set, we performed population-level analyses on the full offspring data set from the final design $(N=129$ offspring individuals from six populations $=7-39$ offspring per population), whereas analyses including the family predictor were done on a subset of the final design that included only families with at least three members, and populations with more than one family (i.e., $N=90$ offspring individuals across 24 families $\times 3-6$ offspring per family, from 5 populations: $8 \mathrm{FD}, 2 \mathrm{HI}, 4 \mathrm{UTB}, 3 \mathrm{WB}$, and 7 WI families) (Table S1).

\subsection{1 | Genetic analyses}

We characterized genetic variation at the population (maternal trees, $N=59$; offspring, $N=129$ ) and family (offspring subset, $N=90$ ) levels. We estimated (i) allelic richness (i.e., rarefied mean number of alleles per locus within each population/family; function allelic.richness from hierfstat package-Goudet, 2005); (ii) the proportion of fixed loci (as the proportion of alleles with a minor allele frequency-MAF-equal to 1; MAF estimated with the function minorAllele from adegenetJombart, 2008); and (iii) the mean and standard deviation of observed gene diversity, and heterozygosity per locus (function basic.stats within hierfstat which is based on (Nei, 1987). We used SNPs with no missing values: 49,706, 885, and 6912 SNPs in maternal trees, offspring, and offspring subsets, respectively. We also estimated overall observed heterozygosity, mean within-population genetic diversity, total genetic diversity across populations, total among-population genetic diversity, and overall population differentiation for each data set with the function basic.stats. We were unable to estimate inbreeding coefficients with our data due to the limited number of polymorphic SNPs since (Goudet et al., 2018) report that at least 1000 polymorphic markers are required.

We tested for genetic differentiation within and among populations of $R$. mangle using several methods. With the maternal trees data, we tested for differentiation among populations with three different approaches. First, we used an analysis of molecular variance (AMOVA) within the function poppr.amova in poppr (Kamvar et al., 2014) and the model $\mathrm{y} \sim$ population. To test the significance of the model we ran a randomization test with 999 permutations on the output of the AMOVA using the function randtest from the ade4 package (Dray \& Dufour, 2007). Second, we obtained overall $F_{\text {st }}$ and 
pairwise $F_{\text {st }}$ values using the functions wc and genet.dist, respectively from the package hierfstat, and calculated the confidence intervals of the pairwise $F_{\text {st }}$ values using the function boot.ppfst, from the same package, with 999 permutations to determine whether $F_{\text {st }}$ values were significantly different from zero, that is, to find evidence of significant population differentiation. Finally, we calculated the G-statistic using the function gstat.rand test with 999 simulations implemented in the package hierfstat. To reduce computation time of the gstat.rand test analysis, we randomly subsampled 3000 from 49,796 SNPs with no missing values for the maternal trees. Finally, to identify SNPs that could be under selection, we tested for outliers with bayescan (version 2.1, Fischer et al., 2011; Foll \& Gaggiotti, 2008). SNPs were identified as significant if the false discovery rate (FDR; Benjamini \& Hochberg, 1995) was below 0.05 .

For the offspring data, we tested for differentiation among families (i.e., among maternal trees) within populations and among populations $(N=90)$. As with the maternal tree data set, we performed an AMOVA with the model: $\mathrm{y} \sim$ population + family (population). We also completed overall and pairwise $F_{\text {st }}$ as well as G-statistics analyses using all 3786 SNPs with no missing values for the offspring data set.

We quantified the relationship between genome-wide genetic variation and population of origin in the case of the maternal trees, and population and family in the case of the offspring $(N=90)$, using redundancy analysis (RDA). RDA is an ordination technique that summarizes the main patterns of variation in the response matrix, that is, the scaled allele frequency matrix created from the SNP data (obtained using the function scaleGen from adegenet with NA.method set to "mean"), which can be explained by our explanatory variables, that is, population (for the maternal trees) or population and family (for the offspring). We used the function rda implemented within the vegan package (Oksanen et al., 2017) to fit the following models:

1) maternal trees allele frequency matrix $\sim$ population;

2) offspring allele frequency matrix $\sim$ population + family.

We tested the significance of the variation explained by our explanatory variables using a Monte Carlo permutation test with 999 permutations and obtained adjusted $R^{2}$ using the function RsquareAdj from the vegan package. We corrected $p$ values for multiple testing using the false discovery rate ("fdr") method implemented with the p.adjust function in the base package of $\mathrm{R}$.

All analyses were also run on a second set of data where we removed SNPs that were not in HardyWeinberg equilibrium (function hw.test from the pegas package-Paradis, 2010), based on (Guo \& Thompson, 1992) and SNPs with a MAF $\leq 1 \%$. The results of these analyses are presented in Tables $\mathrm{S} 2-\mathrm{S} 5$.

\subsection{2 | Epigenetic analyses}

For both maternal trees $(N=59)$ and offspring plants $(N=90)$, we calculated the DNA methylation level at each SMP and individual sample as the number of reads mapping to one position showing evidence of methylation divided by the total number of reads mapping to that position. Then, we calculated mean and standard deviation of DNA methylation for each sequence context (CG, $\mathrm{CHG}, \mathrm{CHH}$ ) and across all contexts for each population (maternal trees and offspring) and for each family (offspring), as well as the proportion of fixed loci for no methylation (i.e., methylation level $\leq 5 \%$ across $\geq 95 \%$ of the samples) and for full methylation (i.e., methylation level $\geq 95 \%$ across $\geq 95 \%$ of the samples) for each data set.

We used a multivariate test for homogeneity of dispersions to estimate epigenetic diversity, that is, variation in DNA methylation levels, for the maternal trees and offspring datasets following the approach of Anderson et al. (2006), which measures the average distance from each individual to their group centroid in a multivariate space using a dissimilarity measure. In line with this interpretation, we argue that the distance from each individual sample to its population centroid in a multivariate space generated using an epigenetic distance matrix provides an estimate of the extent of the variation in DNA methylation, that is, epigenetic variation. Then, the average distance of each population can be compared to look for significant differences in the amount of epigenetic variation among populations. To do so, we generated pairwise epigenetic distance matrices for maternal trees and offspring by calculating the average difference in DNA methylation level across all cytosines between each pair of samples. Then, we used this matrix to calculate the distance between each individual sample and its population centroid using the function betadisper from the vegan package. We tested for differences in dispersion among populations using a permutation-based test of multivariate homogeneity of group dispersions on the output of betadisper with 9999 permutations. When this test was significant, we used Tukey's Honest significant difference test to check which populations differed in their average distance to the centroid, that is, in their levels of epigenetic variation. Finally, to compare genetic and epigenetic diversity levels, we used this approach to calculate the distance from each sample to its population centroid using genetic distance matrices. Genetic distances were calculated as the average distance 
of all per-SNP differences between two individuals. For each SNP, the distance was set to 0 if both alleles were identical, 1 if both alleles were different, and 0.5 if one allele was different.

We tested for differences in overall DNA methylation levels, that is, the average percent DNA methylation per individual, and its standard deviation. We calculated average and standard deviation of percent DNA methylation for each separate sequence context (i.e., CG, CHG, and $\mathrm{CHH}$ ) or across all sequence contexts, and then we used a general linear model (functions $\mathrm{lm}$ and ANOVA) to test for significant differences among populations (maternal trees data) or among populations and families nested within populations (offspring data).

To assess the effect of population (for the maternal trees), and population and family (for the offspring) on genome-wide epigenetic variation, for each separate sequence context (i.e., $\mathrm{CG}, \mathrm{CHG}$, and $\mathrm{CHH}$ ) or across all sequence contexts, with and without accounting for their genetic structure, we used RDA and partial constrained RDA, respectively. Partial constrained RDA allows for "conditioning" the analysis of epigenetic variation with genetic data which we summarized with principal component analysis (PCA). The use of the "family" term in this analysis represents a composite of the maternal genetic and nongenetic contributions to the offspring epigenetic patterns since this term is not simply defined by maternal sequence patterns. Instead, the "family" term is a categorical representation such that data for the propagules is explained by the association with the maternal tree more generally.

For the RDA, we used only SMPs with complete data, that is, no missing values across samples: 41,164 (3416 in CG, 10,432 in CHG, and 27,316 in $\mathrm{CHH}$ ) for maternal trees and 9038 SMPs (766 in CG, 2549 in CHG, and 5723 in $\mathrm{CHH}$ ) for offspring. As with the genetic analyses, we only used families with at least three members, and populations with more than one family. First, we summarized the genetic data into principal components (PCs). We used the first 13 PCs for the maternal trees data which combined explained $\sim 31 \%$ of the genetic variation in each of the three contexts. For the offspring, we used 12, 13, and 12 PCs for CG, CHG, and $\mathrm{CHH}$ contexts respectively which explained $31 \%, 30 \%$, and $31 \%$ of the variation, respectively. Then, we ran the three following models to predict DNA methylation in the maternal trees:

1) maternal trees DNA methylation matrix population;

2) maternal trees DNA methylation matrix $\sim$ PCs from maternal trees genetic data;

3) maternal trees DNA methylation matrix population + Condition (PCs from maternal trees genetic data).
We ran five similar models to predict DNA methylation in the offspring plants:

1) offspring DNA methylation matrix population;

2) offspring DNA methylation matrix family;

3) offspring DNA methylation matrix $\sim$ PCs from offspring genetic data;

4) offspring DNA methylation matrix population + Condition (PCs from offspring genetic data);

5) offspring DNA methylation matrix $\sim$ family + Condition (PCs from offspring genetic data).

As for the genetic data, we tested the significance of the variation explained by our explanatory variables using a Monte Carlo permutation test and obtained adjusted $R^{2}$, and adjusted $p$ values for multiple testing using the FDR method.

To test how much of the epigenetic (methylation) differentiation could be attributed to differences among populations, and how much of the epigenetic variation was associated with the populations after controlling for differences in sequence variation physically linked to the epigenetic variation, we modeled the average DNA methylation level of each $50-250 \mathrm{bp}$ long fragment in response to the sequence context (CTXT), the population (POP) and its interaction with context (CTXT:POP), and the genotype of the fragment (GENO) and its interaction with context (CTXT:GENO) fitted in this order (percent methylation CTXT + POP + CTXT:POP + GENO + CTXT:GENO). We then compared this result to an alternative model in which GENO and POP and their interactions with CTXT were switched (percent methylation CTXT + GENO + CTXT:GENO + POP + CTXT:POP). We ran these models in $\mathrm{R}$ with the function ANOVA() that uses type-I (i.e., sequential) tests.

Therefore, the first model tests for epigenetic differentiation between populations irrespective of the underlying sequence differences, and the second model tests whether there was epigenetic differentiation between populations that could not be explained by the underlying DNA sequence. For the offspring, we used similar models but further included the family term. We only used fragments which passed the coverage filters described above. We used the functions $\mathrm{lm}$ and ANOVA in $\mathrm{R}$ (version 3.6.1). Results from all reference sequences were collected and $p$ values for each term were adjusted for multiple testing by the FDR method (Benjamini \& Hochberg, 1995). As noted previously (van Moorsel et al., 2019), this model is a good proxy for close-cis associations. However, given that it does not account for far-cis or trans associations, it tends to overestimate the proportion of epigenetic variation that is unlinked to genetic variation. 
Finally, we identified differentially methylated cytosine positions (DMPs) between pairs of populations for the maternal trees and the offspring datasets using the dispersion shrinkage for sequencing data (DSS) package in (Park \& Wu, 2016) and adjusted for false discovery with FDR. This package models the DNA methylation level at each position within each group using a betabinomial distribution with arcsine link function, and then performs Wald tests to detect differential methylation between groups at each position. Many studies have shown that DMPs are not as likely to influence function as methylation differences across large chromosomal stretches (DMRs). However, DMRs are difficult to define even in whole genome studies and the short fragments that results from epiGBS libraries are typically $<250 \mathrm{bp}$, contain only a few cytosine positions, and prevent statistical confidence for calling DMRs (Paun et al., 2019; Richards et al., 2017).

\section{3 | RESULTS}

\section{1 | Population genetics}

A high percentage of the loci were fixed (i.e., $\mathrm{MAF}=1$ ) in the maternal tree data set (62\%), whereas this percentage was lower in the offspring (12\% and $15 \%$ in the offspring grouped by population and family, respectively). We found low levels of genetic diversity among populations, with observed gene diversity values per locus ranging between 0.009 and 0.012 and heterozygosity between 0.010 and 0.014 for the maternal trees. These values ranged between $0.039-0.050$ and $0.050-0.064$ for the offspring when grouped by population, and between 0.023-0.051 and 0.025-0.056 for the offspring when grouped by family (Table 1). Mean allelic richness averaged 1.1, 1.2, and 1.1 for the maternal trees, offspring by population, and offspring by family respectively (Table 1). Overall genetic diversity across populations and families was also low, with values of 0.010 , 0.045 , and 0.037 for the maternal trees, offspring by population, and offspring by family respectively, and most of this diversity was found within populations/families (Table 2).

We used three methods to examine genetic structure of the maternal trees, which all provided evidence of significant genetic differentiation among field populations of $R$. mangle. The randomization test performed on the output of the AMOVA was highly significant (Table 3), similar to the Monte Carlo permutation test carried out on the output of the RDA (Table 4), and the test on the significance of the G-statistic $(\mathrm{G}$-stat $=39.9$; $p=0.048)$. Yet, the amount of variation explained by the population of origin was very low. According to the AMOVA, the bulk of the genetic variance is found within (99.4\%) rather than among (0.63\%) populations. Similarly, the RDA showed that population explains only $0.14 \%$ of the genetic variation. We found evidence for significant genetic differentiation between all population pairs except AC-HI and UTB-WI (Figure 2a), the overall $F_{\text {st }}$ was extremely low (0.003) and pairwise $F_{\text {st }}$ values ranged between 0.0005 (UTB-WI) and 0.0081 (WB-WI; Figure 2a).

We visualized the genetic data by means of PCA using the complete SNP data set as well as the 5\% most differentiated SNPs, finding that a clear separation among populations was only possible when using the 5\% most differentiated loci (Figures 3 and Figure S1). We found that the significant genetic differentiation among maternal trees of $R$. mangle yielded by our statistical analyses was principally due to the distinctness of WB, and possibly of HI, from the rest of the populations. The separation of WB from all other populations was also reflected in the higher pairwise $F_{\text {st }}$ values between WB and the others (Figure 2a). Finally, our analysis yielded 277 SNPs showing significant signs of differences among maternal trees of $R$. mangle collected in the field. The 277 SNPs were located in 111 different sequence fragments, out of which 26 had a high sequence similarity to known genes (descriptions in Table S9). Many of these (i.e., 9) were characterized as "hypothetical" or uncharacterized proteins. The remaining included calcium-transporting ATPase, putative adenylate kinases, or phosphatases.

Results of the genetic analyses on the offspring are similar to that found for the maternal trees; the AMOVA showed significant genetic differentiation among families but this predictor explained only $1 \%$ of the genetic variance. The majority of the variance was found within families (99\%) and population did not significantly explain any proportion of the genetic variation of the offspring (Table 2). On the contrary, the RDA model with population and family did not explain any of the variation of the offspring genetics (Table 4). The G-tests for differentiation between families within populations were significant in two out of five tested populations (WI: Gstat $=171.6, p=0.001$, UTB: G-stat $=131.5, p=0.005)$. Again, the overall $F_{\text {st }}$ value was very low (0.022) and pairwise $F_{\text {st }}$ ranged between -0.0023 and 0.0515 (Figure 2b).

The results of the genetic analyses carried out on the set of data where we removed SNPs that were not in Hardy-Weinberg equilibrium and SNPs with a MAF $\leq 1 \%$ were similar (Tables S2-S5). 
T A B LE 1 Number of alleles (percent of total alleles), allelic richness (i.e., average number of alleles per locus) and mean and standard deviation (SD) of observed gene diversity (Hs) and observed heterozygosity (Ho) per locus for each population (maternal trees and offspring by population) and for each family within population (offspring by family) of Rhizophora mangle (sample sizes shown in parentheses)

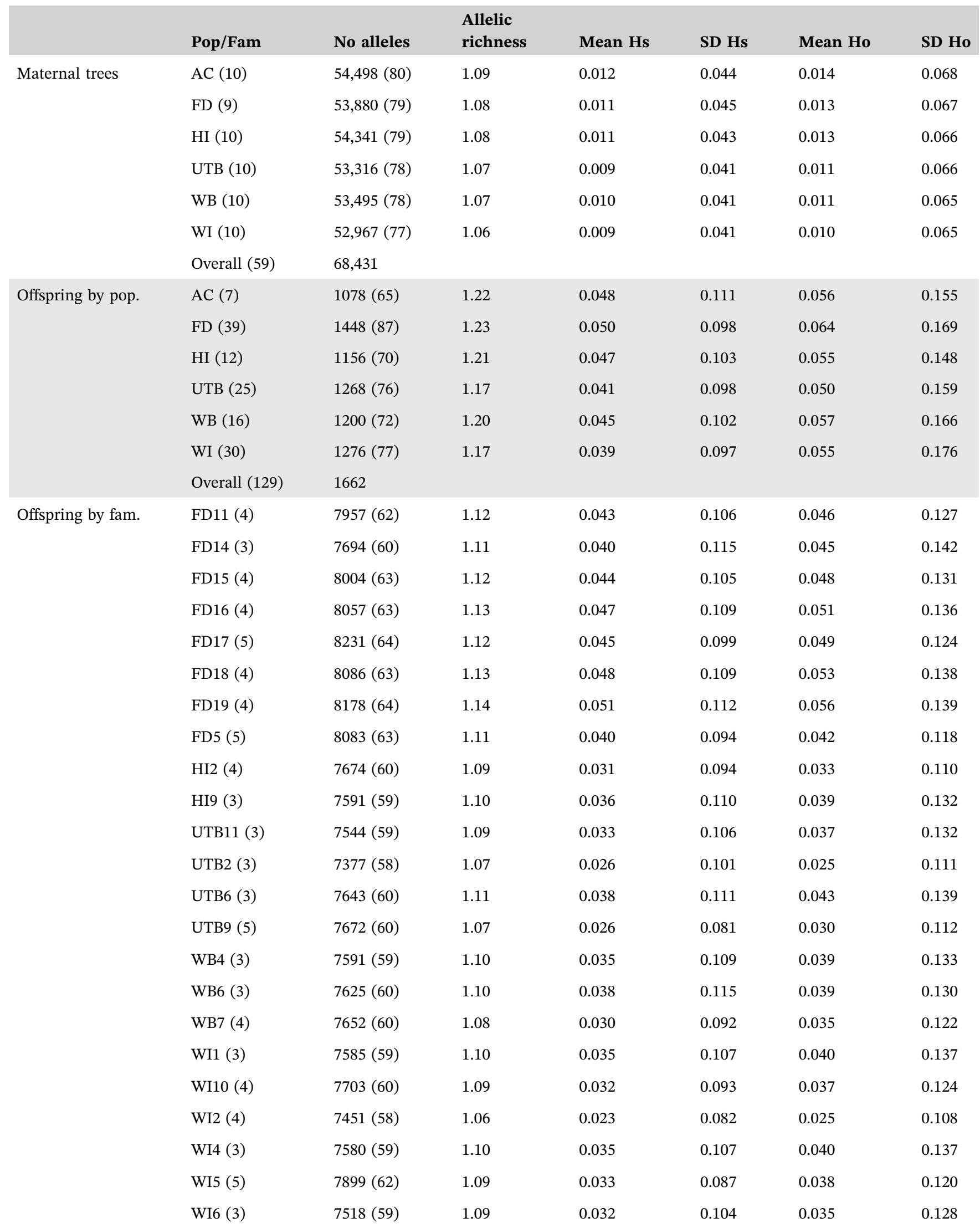


TA B LE 1 (Continued)

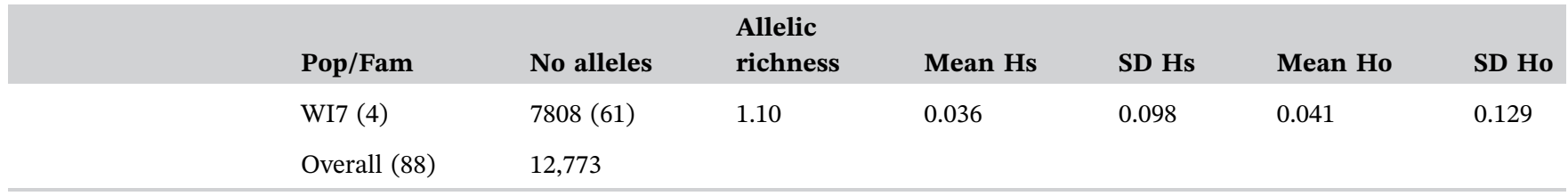

Note: Overall number of alleles is also presented for each data set. Calculated based on SNPs with no missing values (49,706, 885, and 6912 SNPs for maternal trees, offspring by population and offspring by family, respectively).

Abbreviation: SNP, single nucleotide polymorphism.

\section{2 | Population epigenetics}

A large proportion of the SMPs in the maternal tree data set were fixed for no methylation (71\% of the SMPs across all contexts in the whole data set; ranging between $57 \%$ and $67 \%$ individually for each population; Table 5A and 5B), and a small proportion were fixed for full methylation (1.2\% of the SMPs across all contexts in the whole data set; ranging between $2.1 \%$ and $2.9 \%$ individually for each population; Table $5 \mathrm{~A}$ and $5 \mathrm{~B}$ ). The proportion of fixed SMPs was lower in the offspring which showed $<1 \%$ of fixed SMPs for no methylation across all contexts in the whole data set and between $0.4 \%$ and $27 \%$ individually for each population, and $\sim 1 \%$ of fixed SMPs for full methylation across all contexts in the whole data set and between $2.1 \%$ and $6 \%$ individually for each population (Table 5A and 5B).

DNA methylation across all contexts was around 9\% for all populations in the data set for the maternal trees whereas for the offspring this value ranged between $11 \%$ and 17\% (Table S6). Similarly, DNA methylation levels in CG, $\mathrm{CHG}$, and $\mathrm{CHH}$ contexts were close to $28 \%, 23 \%$, and $1 \%$ respectively for all populations in the data set for the maternal trees and slightly higher in the offspring (29\%-33\%, 25\%-30\%, and 4\%-9\% for CG, CHG, and $\mathrm{CHH}$ contexts respectively in the data grouped by population and $29 \%-38 \%, 25 \%-34 \%$, and $3 \%-15 \%$ for CG, CHG, and $\mathrm{CHH}$ contexts respectively in the data grouped by family;

TABLE 2 Overall observed heterozygosity (Ho), mean withinpopulation genetic diversity (Hs), total genetic diversity across populations (Ht), total among-population genetic diversity (Dst), and overall population differentiation (Gst) for each data set based on single nucleotide polymorphisms (SNPs) with no missing values $(49,706,885$, and 6912 SNPs for maternal trees, offspring by population and offspring by family, respectively)

\begin{tabular}{|llllll|} 
& Ho & Hs & Ht & Dst & Gst \\
\hline Maternal trees & 0.0120 & 0.0103 & 0.0103 & 0.0000 & 0.002 \\
\hline Offspring by pop. & 0.0561 & 0.0450 & 0.0454 & 0.0003 & 0.007 \\
\hline Offspring by fam. & 0.0403 & 0.0365 & 0.0368 & 0.0003 & 0.007
\end{tabular}

Note: Measures based on Nei (1987).
Table S6). The standard deviation of DNA methylation levels averaged $26 \%, 25 \%$, and $27 \%$ across all contexts for the maternal trees, offspring by population and offspring by family respectively, and $39 \%, 38 \%$, and $40 \%$ in the CG context, $41 \%, 39 \%$, and $40 \%$ in the CHG context, and $1 \%$, $6 \%$, and $10 \%$ in the $\mathrm{CHH}$ context, for the maternal trees, offspring by population and offspring by family respectively (Table S6). The average distances from each sample to its population centroid estimated as a proxy of the amount of epigenetic variation range between 0.02 and 0.03 in the maternal trees and between 0.05 and 0.08 in the offspring (Figure 4). The tests for homogeneity of multivariate dispersions were significant for both the maternal trees and the offspring datasets $(F=23.5$, $p<0.001 ; F=16.0, p<0.001$, respectively) revealing significant differences in the levels of epigenetic diversity among populations in both datasets. The multiple pairwise comparisons within each data set showed that these differences were due to the greater epigenetic diversity found in WB in the maternal trees. In the offspring, FD, HI, and WB showed higher levels of epigenetic diversity than UTB and WI (Figure 4). The average distances to centroid estimated with the genetic data were an order of magnitude lower for the mothers (ranging between 0.007

TABLE 3 Analysis of molecular variance (AMOVA) carried out on the maternal trees and offspring datasets separately

\begin{tabular}{|c|c|c|c|}
\hline & Sigma & $\%$ & $\phi$ \\
\hline \multicolumn{4}{|l|}{ Maternal trees } \\
\hline Among populations & 1.6789 & 0.629 & \multirow[t]{2}{*}{$0.0063^{* * *}$} \\
\hline Within populations & 265.40 & 99.37 & \\
\hline \multicolumn{4}{|l|}{ Offspring } \\
\hline Among populations & 0.0684 & 0.016 & $0.0002^{\mathrm{ns}}$ \\
\hline Among families & 4.4994 & 1.026 & $0.0103^{* * *}$ \\
\hline Within families & 433.95 & 98.96 & $0.0104^{* * *}$ \\
\hline
\end{tabular}


T A B LE 4 Results of the redundancy analysis (RDA) showing the percentage of genetic and epigenetic variance explained by population (in maternal trees data set), and population and family (in offspring data set) with and without adjusting for the variance explained by the genetic component

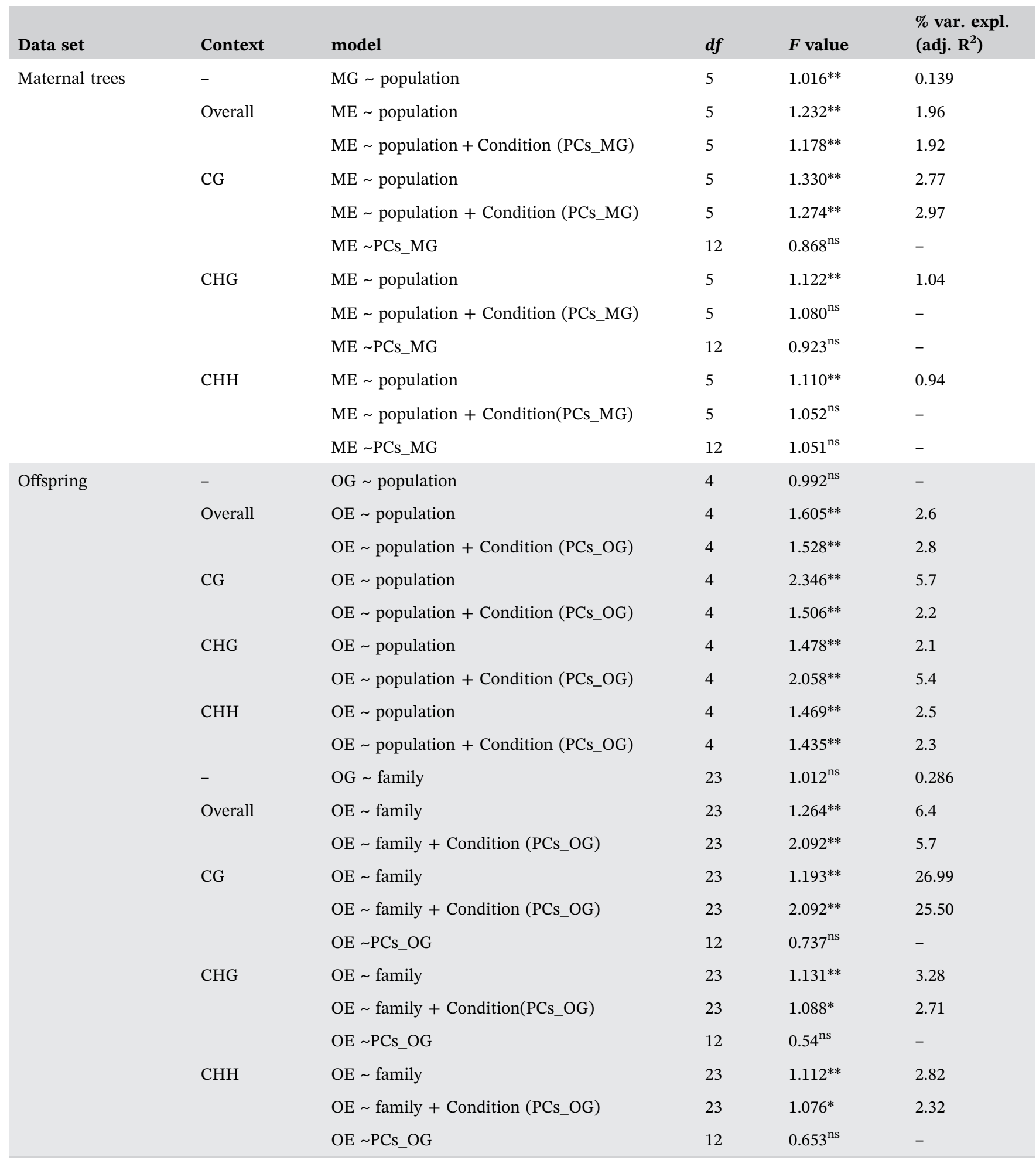

Note: The output of the Monte Carlo permutation test ( $F$ value and significance) is also shown.

Abbreviations: Context, sequence context for DNA methylation; $d f$, degrees of freedom. \% var. expl. (adj. $R^{2}$ ), percent of variance explained as the $R^{2}$ adjusted for multiple comparisons; MG, maternal trees genetic matrix; ME, maternal trees epigenetic matrix; ns, not significant; PCs_MG, matrix of principal components summarizing the maternal trees genetics; PCs_OG, matrix of principal components summarizing the offspring's genetics.

${ }^{* *} p<0.01,<0.01,{ }^{*} p<0.05,<0.05$. 
(a)

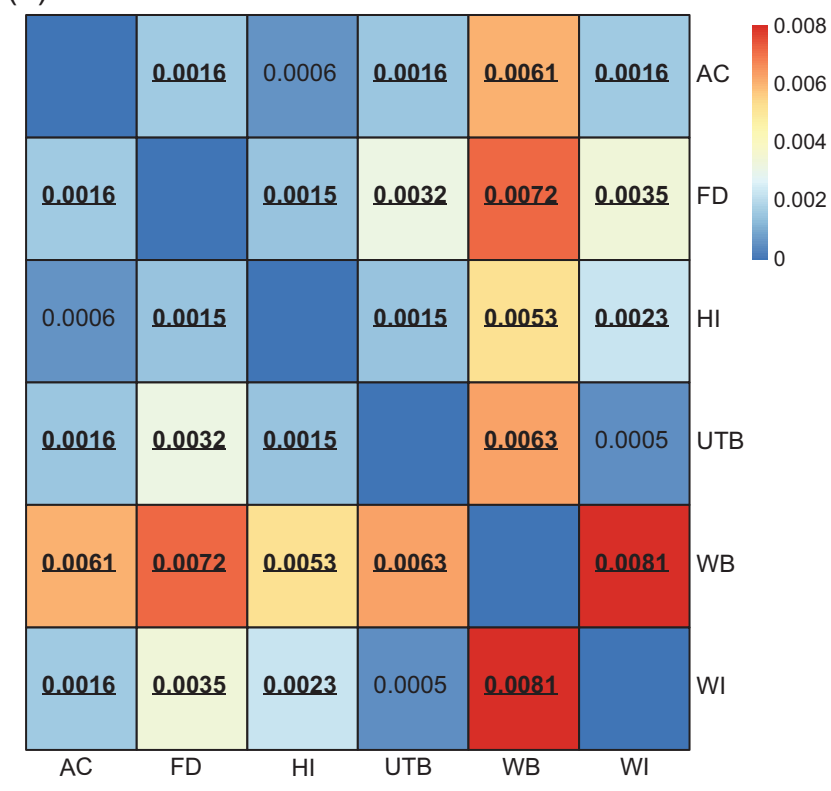

(b)

\begin{tabular}{|c|c|c|c|c|c|c|c|c|c|c|c|c|c|c|c|c|c|c|c|c|c|c|c|c|}
\hline & 0.0095 & 0.0035 & 0.0003 & 0.0053 & 0.0049 & $\underline{0.0108}$ & 0.0025 & 0.0069 & 0.0133 & -0.0005 & 0.0038 & 0.0136 & 0.0051 & 0.0178 & 0.0031 & 0.0157 & 0.0182 & 0.0094 & 0.0342 & 0.0089 & 0.0197 & $\underline{0.0180}$ & 0.0111 & FD11 \\
\hline 0.0095 & & 0.0180 & 0.0003 & 0.0068 & 0.0189 & 0.0193 & 0.0091 & 0.0183 & 0.0191 & 0.0040 & 0.0098 & 0.0000 & 0.0201 & $-0.0006 \mid$ & 0.0067 & $-0.0049 \mid$ & $|-0.0065|$ & -0.0037 & 0.0100 & 0.0010 & 0.0071 & 0.0200 & 0.0049 & FD14 \\
\hline 0.0035 & 0.0180 & & $|-0.0019|$ & 0.0016 & 0.0065 & -0.0011 & 0.0144 & 0.0169 & 0.0155 & 0.0040 & 0.0039 & 0.0166 & 0.0174 & 0.0222 & 0.0048 & 0.0260 & 0.0283 & 0.0232 & 0.0477 & 0.0112 & 0.0339 & 0.0127 & 0.0190 & FD15 \\
\hline 0.0003 & 0.0003 & -0.0019 & & -0.0023 & 0.0005 & 0.0031 & 0.0043 & 0.0097 & 0.0008 & -0.0021 & $|-0.0035|$ & $\mid-0.0007$ & 0.0096 & $-0.0001 \mid$ & 0.0009 & 0.0051 & 0.0064 & 0.0050 & $\underline{0.0182}$ & -0.0026 & 0.0192 & $=0.0083$ & $\underline{0.0085}$ & FD16 \\
\hline 0.0053 & 0.0068 & 0.0016 & -0.0023 & & 0.0066 & 0.0060 & 0.0129 & 0.0137 & 0.0147 & 0.0013 & $|-0.0010|$ & 0.0040 & 0.0120 & 0.0094 & 0.0003 & 0.0124 & 0.0142 & 0.0087 & 0.0282 & -0.0038 & 0.0156 & -0.0018 & 8.0043 & FD17 \\
\hline 0.0049 & 0.0189 & 0.0065 & 0.0005 & 0.0066 & & 0.0074 & 0.0131 & 0.0209 & 0.0188 & 0.0139 & 0.0106 & 0.0169 & 0.0240 & 0.0222 & 0.0088 & 0.0302 & 0.0309 & 0.0235 & 0.0485 & 0.0122 & 0.0322 & 20.0198 & 0.0195 & FD18 \\
\hline 0.0108 & 0.0193 & $-0.0011 \mid$ & 0.0031 & 0.0060 & 0.0074 & & 0.0149 & 0.0158 & 0.0082 & 0.0108 & 0.0071 & 0.0162 & 0.0203 & 0.0143 & 0.0130 & 0.0280 & $\underline{0.0295}$ & 0.0270 & 0.0500 & $\underline{0.0170}$ & 0.0413 & 0.0121 & 0.0231 & FD19 \\
\hline 0025 & 0.0091 & 0.0144 & 0.0043 & 0.0129 & 0.0131 & 0.0149 & & $|-0.0013|$ & 0.0073 & 0.0048 & $|-0.0047|$ & 0.0062 & 0.0049 & 0.0087 & 0.0089 & 0.0092 & 0.0133 & 0.0091 & 0.0156 & 0.0127 & 0.0228 & 0.0103 & 0.0173 & FD5 \\
\hline 0.0069 & 0.0183 & 0.0169 & 0.0097 & 0.0137 & 0.0209 & 0.0158 & $|-0.0013|$ & & 0.0070 & 0.0082 & 0.0146 & 0.0256 & $0.0050 \mid$ & 0.0178 & 0.0126 & \begin{tabular}{|l|}
0.0198 \\
\end{tabular} & 0.0176 & 0.0136 & 0.0227 & 0.0250 & 0.0371 & 0.0325 & 0.0329 & $\mathrm{HI} 2$ \\
\hline 0133 & 0.0191 & 0.0155 & 0.0008 & 0.0147 & 0.0188 & 0.0082 & 0.0073 & 0.0070 & & 0.0177 & 0.0230 & 0.0250 & 0.0221 & 0.0167 & 0.0127 & 0.0291 & 0.0227 & 0.0231 & 0.0344 & 0.0302 & 0.0497 & 0.0413 & 0.0388 & HI9 \\
\hline .0005 & 0.0040 & 0.0040 & -0.0021 & 0.0013 & 0.0139 & 0.0108 & 0.0048 & 0.0082 & 0.0177 & & 0.0080 & 0.0137 & 0.0007 & 0.0188 & $|-0.0071|$ & 0.0063 & 0.0105 & 0.0003 & 0.0298 & 0.0029 & 0.0031 & 0.0209 & 0.0087 & UTB11 \\
\hline 0.0038 & 0.0098 & 0.0039 & -0.003 & -0.0010 & 0.0106 & 0.0071 & $|-0.0047|$ & 0.0146 & 0.0230 & 0.0080 & & 0.0191 & 0.0210 & 0.0223 & $|-0.0022|$ & 0.0264 & 0.0246 & 0.0158 & 0.0431 & 0.0152 & 0.0267 & 0.0139 & 0.0162 & UTB2 \\
\hline 0.0136 & 0.0000 & 0.0166 & $|-0.0007|$ & $0.0040 \mid$ & 0.0169 & $\underline{0.0162}$ & 0.0062 & 0.0256 & $\underline{0.0250}$ & 0.0137 & 0.0191 & & 0.0335 & 0.0063 & 0.0081 & 0.0099 & 0.0018 & 0.0052 & $\underline{0.0261}$ & 0.0021 & 0.0198 & $\underline{0.0259}$ & 0.0105 & UTB6 \\
\hline 0.0051 & 0.0201 & 0.0174 & 0.0096 & 0.0120 & 0.0240 & 0.0203 & 0.0049 & 0.0050 & 0.0221 & 0.0007 & 0.0210 & 0.0335 & & 0.0266 & 0.0143 & 0.0186 & 0.0188 & 0.0145 & 0.0306 & 0.0299 & 0.0208 & 0.0371 & 0.0259 & UTB9 \\
\hline 0.0178 & $|-0.0006|$ & 0.0222 & $|-0.0001|$ & 0.0094 & 0.0222 & 0.0143 & 0.0087 & 0.0178 & 0.0167 & 0.0188 & 0.0223 & 0.0063 & 0.0266 & & 0.0116 & 0.0048 & -0.0013 & 0.0109 & 0.0154 & 0.0118 & 0.0225 & 0.0406 & 0.0171 & WB4 \\
\hline 0031 & 0.0067 & 0.0048 & 0.0009 & 0.0003 & 0.0088 & $\underline{0.0130}$ & 0.0089 & 0.0126 & 0.0127 & -0.0071 & $|-0.0022|$ & 0.0081 & $\underline{0.0143}$ & 0.0116 & & 0.0114 & 0.0220 & 0.0056 & $\underline{0.0283}$ & -0.0061 & 0.0097 & 0.0033 & $\underline{0.0077}$ & WB6 \\
\hline 0.0157 & $|-0.0049|$ & 0.0260 & 0.0051 & 0.0124 & 0.0302 & 0.0280 & 0.0092 & 0.0198 & 0.0291 & 0.0063 & 0.0264 & 0.0099 & 0.0186 & 0.0048 & 0.0114 & & -0.0043 & -0.0011 & 0.0113 & 0.0106 & 0.0080 & 0.0363 & 0.0120 & WB7 \\
\hline 0.0182 & $|-0.0065|$ & 0.0283 & 0.0064 & 0.0142 & 0.0309 & 0.0295 & 0.0133 & 0.0176 & 0.0227 & 0.0105 & 0.0246 & 0.0018 & 0.0188 | & $|-0.0013|$ & 0.0220 & $|-0.0043|$ & & 0.0043 & 0.0083 & 0.0113 & 0.0178 & 0.0327 & 0.0169 & WI1 \\
\hline 0.0094 & $|-0.0037|$ & 0.0232 & 0.0050 & 0.0087 & 0.0235 & $\underline{0.0270}$ & 0.0091 & 0.0136 & 0.0231 & 0.0003 & 0.0158 & 0.0052 & 0.0145 & 0.0109 & 0.0056 & $-0.0011 \mid$ & 0.0043 & & 0.0087 & -0.0009 & 0.0020 & $\underline{0.0172}$ & 0.0054 & WI10 \\
\hline .0342 & 0.0100 & $0.0477 \mid$ & 0.0182 & 0.0282 & $|0.0485|$ & 0.0500 & 0.0156 & 0.0227 & 0.0344 & 0.0298 & 0.0431 & 0.0261 & 0.0306 & 0.0154 & 0.0283 & 0.0113 & 0.0083 & 0.0087 & & 0.0326 & 0.0273 & 0.0515 & 0.0379 & WI2 \\
\hline 0.0089 & 0.0010 & 0.0112 & -0.002 & -0.003 & 0.0122 & 0.0170 & 0.0127 & 0.0250 & 0.0302 & 0.0029 & 0.0152 & 0.0021 & 0.0299 & 0.0118 & $|-0.0061|$ & 0.0106 & 0.0113 & $\mid-0.0009$ & 0.0326 & & 0.0053 & 0.0221 & 0.0009 & WI4 \\
\hline 0.0197 & 0.0071 & 0.0339 & 0.0192 & 0.0156 & 0.0322 & 0.0413 & 0.0228 & 0.0371 & 0.0497 & 0.0031 & 0.0267 & 0.0198 & 0.0208 & 0.0225 & 0.0097 & 0.0080 & 0.0178 & 0.0020 & 0.0273 & 0.0053 & & 0.0289 & 0.0065 & W15 \\
\hline 0.0180 & 0.0200 & 0.0127 & 0.0083 & -0.0018 & 0.0198 & 0.0121 & 0.0103 & 0.0325 & 0.0413 & 0.0209 & 0.0139 & 0.0259 & $0.0371 \mid$ & 0.0406 & 0.0033 & 0.0363 & 0.0327 & 0.0172 & 0.0515 & 0.0221 & 0.0289 & & 0.0138 & WI6 \\
\hline 0111 & 0.0049 & 0.0190 & 0.0085 & 0.0043 & 0.0195 & 0.0231 & 0.0173 & 0.0329 & 0.0388 & 0.0087 & 0.0162 & 0.0105 & 0.0259 & 0.0171 & 0.0077 & 0.0120 & 0.0169 & 0.0054 & 0.0379 & 0.0009 & 0.0065 & 0.0138 & & W17 \\
\hline & & & & & & & & & & & & & & & & & & & & & & & & \\
\hline
\end{tabular}

FIGURE 2 Pairwise $F_{\text {st }}$ values between field populations of Rhizophora mangle in the maternal tree data (a), and between families within populations in the offspring data (b). Bold underlined values indicate significantly genetically differentiated population/family pairs, that is, $F_{\text {st }}$ values different from 0 [Color figure can be viewed at wileyonlinelibrary.com] 
(a)

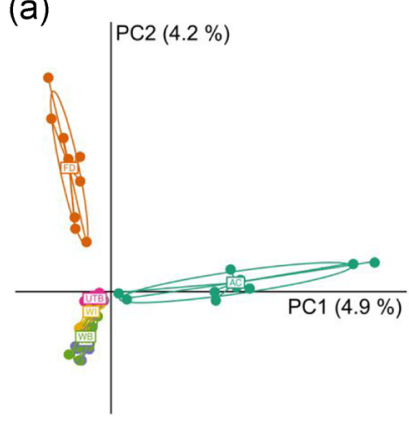

(b)

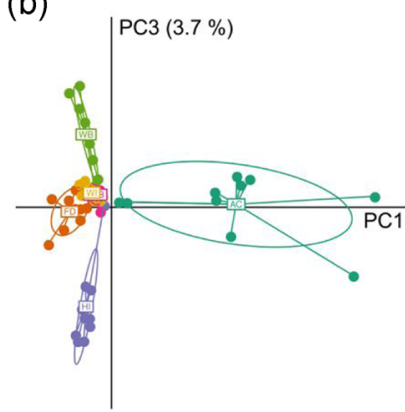

(c)

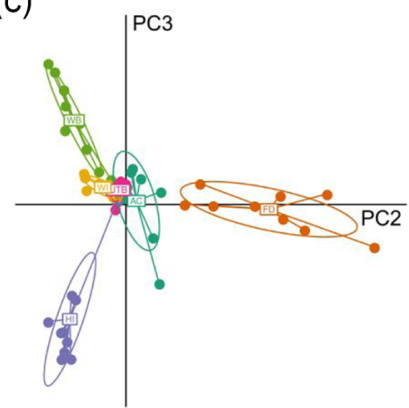

F I G URE 3 Visualization of the genetic structure of the maternal trees of Rhizophora mangle using only the 5\% of the most differentiated SNPs based on Jost's D with a principal component analysis (the 95\% percentile in the entire data set, Jost 2008). Only SNPs without any NAs were used. Data were scaled with the function adegenet::scaleGen() and the PCA was done with the function adegenet::dudi.pca() without further centering and scaling. Each dot represents one maternal tree; labels with the population identifiers represent each population centroid. See also Figure S1 for similar depiction of genetic structure of offspring and epigenetic structure in maternal trees and offspring. PCA, principal component analysis; SNP, single nucleotide polymorphisms [Color figure can be viewed at wileyonlinelibrary.com]

and 0.01 ), and between $2.5 \times$ and $4 \times$ times lower for the offspring (data not shown).

The linear models that test for differences in average DNA methylation levels and standard deviation in DNA methylation showed that population of origin significantly explains $75 \%$ of the variation on average and $52 \%$ of the variation in standard deviation for the maternal trees if data from all sequence contexts were used. Within individual contexts, the numbers were similar but there was no significant association between population of origin and average DNA methylation in the CG context (Table S7). Among the offspring, the family term significantly explained $79 \%$ of the variation in average and $74 \%$ of the variation in standard deviation if data from all sequence contexts were used. At least half could be attributed to differences between population ( $47 \%$ of the variation in average and $37 \%$ of the variation in standard deviation). Within individual sequence contexts, the results were similar for the average DNA methylation levels. However, the association between population of origin and variation in standard deviation in CG and CHG context were not significant (Table S7).

The RDA analysis on the effect of population (for the maternal trees), and population and family (for the offspring) on genome-wide epigenetic variation showed that epigenetic variation is significantly structured in both datasets. Population significantly explained $1.96 \%$ of the total epigenetic variation across all sequence contexts in the maternal trees and $2.6 \%$ of the epigenetic variation in offspring; family explained $6.4 \%$ of the total epigenetic variation across all sequence contexts in the offspring. Additionally, population explained $2.77 \%, 1.04 \%$, and $0.94 \%$ of the epigenetic variation in $\mathrm{CG}, \mathrm{CHG}$, and $\mathrm{CHH}$ respectively for the maternal trees (Table 3). For the offspring, family explained a greater percent of epigenetic variation with $26.99 \%, 3.28 \%$, and $2.82 \%$ in $\mathrm{CG}, \mathrm{CHG}$, and $\mathrm{CHH}$ respectively against the $5.7 \%, 2.1 \%$, and $2.5 \%$ in $\mathrm{CG}$, $\mathrm{CHG}$, and $\mathrm{CHH}$ respectively explained by population (Table 3).

The partial RDA in which the same models were conditioned on the maternal and offspring genetic data (based on PCs) showed similar results for the effect of population in maternal trees (explaining $1.92 \%$ of the variation) and offspring (2.8\%), and of the family term in the offspring (5.7\%; Table 3) across all sequence contexts. However, when examining each context separately for the maternal trees, the effect of population only remains significant in the CG context and explains $2.97 \%$ of the variation (Table 3). For the offspring, both population and family remain significant in all contexts after accounting for the offspring's genetic component; population explains similar levels of the variation in $\mathrm{CG}$, $\mathrm{CHG}$, and $\mathrm{CHH}$ contexts respectively, while family explains $25.5 \%, 2.7 \%$, and $2.3 \%$ of the variation in CG, CHG, and $\mathrm{CHH}$ contexts, respectively. The genetic component does not significantly explain any of the epigenetic variation in either the maternal or the offspring data or across all contexts and each sequence context separately (Table 3).

The differential methylation analysis with DSS comparing DNA methylation levels at individual cytosines between pairs of populations yielded between $0.02 \%$ and $1.1 \%$ significantly differentially methylated cytosines in the maternal trees and between $0.1 \%$ and $4.5 \%$ significant cytosines in the offspring (Table S10). For maternal trees, we found that the most pronounced differences were between WB versus WI (1.13\% significant Cs) and between WB versus UTB (1.08\% significant Cs). We found almost no differences between AC versus FD, HI, UTB, and between UTB versus FD, HI, WI $(\leq 0.05 \%$ significant Cs). Most of the annotated DMPs were located in genes 
TABLE 5 Number and proportion (within parentheses) of fixed cytosine positions for no methylation (fixed unmeth Cs, $0 \%$ methylation) and full methylation (fixed fullmeth Cs, $100 \%$ methylation)

\begin{tabular}{|c|c|c|c|}
\hline & Context & $\begin{array}{l}\text { Fixed } \\
\text { unmeth Cs }\end{array}$ & $\begin{array}{l}\text { Fixed } \\
\text { fullmeth Cs }\end{array}$ \\
\hline \multicolumn{4}{|l|}{ (A) } \\
\hline \multirow{4}{*}{$\begin{array}{l}\text { Maternal } \\
\quad \text { trees }(N=59)\end{array}$} & total & $29,099(70.7)$ & $510(1.24)$ \\
\hline & CG & $1547(45.3)$ & $30(0.88)$ \\
\hline & $\mathrm{CHG}$ & $6224(59.7)$ & $480(4.6)$ \\
\hline & $\mathrm{CHH}$ & $21,328(78.1)$ & 0 \\
\hline \multirow{4}{*}{$\begin{array}{l}\text { Offspring } \\
\qquad(N=90)\end{array}$} & total & $7(0.08)$ & $88(0.97)$ \\
\hline & CG & 0 & $3(0.39)$ \\
\hline & $\mathrm{CHG}$ & 0 & $25(0.98)$ \\
\hline & $\mathrm{CHH}$ & $7(0.12)$ & $60(1.05)$ \\
\hline \multicolumn{4}{|l|}{ (B) } \\
\hline & Pop. & $\begin{array}{l}\text { fixed } \\
\text { unmeth Cs }\end{array}$ & $\begin{array}{l}\text { fixed } \\
\text { fullmeth Cs }\end{array}$ \\
\hline \multirow{6}{*}{$\begin{array}{l}\text { maternal } \\
\qquad \text { trees }(N=59)\end{array}$} & $\mathrm{AC}$ & $25,072(60.9)$ & $856(2.1)$ \\
\hline & FD & $26,041(63.3)$ & $1196(2.9)$ \\
\hline & $\mathrm{HI}$ & $26,410(64.2)$ & $1123(2.7)$ \\
\hline & UTB & $26,590(64.6)$ & $937(2.3)$ \\
\hline & WB & $23,328(56.7)$ & $1058(2.6)$ \\
\hline & WI & $27,387(66.5)$ & $1061(2.6)$ \\
\hline \multirow{5}{*}{$\begin{array}{l}\text { Offspring } \\
\qquad(N=90)\end{array}$} & FD (33) & $32(0.4)$ & $316(3.5)$ \\
\hline & HI (7) & 1239 (13.7) & $540(6.0)$ \\
\hline & UTB (14) & $2452(27.1)$ & $546(6.0)$ \\
\hline & WB (10) & $441(4.9)$ & $314(3.5)$ \\
\hline & WI (26) & $559(6.2)$ & $185(2.1)$ \\
\hline
\end{tabular}

Note: (A) across all samples within each data set (maternal trees and offspring) and (B) for each population (Pop.) within each data set (maternal trees and offspring) based on SMPs without missing values (41,164 and 9038 SMPs for the maternal trees and offspring, respectively). The proportions for each context refer to the number of fixed cytosines with respect to the total number of cytosines in that context.

Abbreviation: single methylation polymorphisms.

(23\% on average), and only few of them were located in repeats and transposons (on average, $7 \%$ and $2 \%$ respectively); in general, the number of DMPs tended to be higher in the CHH context (Table S10). In the offspring, we found the higher number of significant Cs were between WI versus FD (4.5\%), WI versus HI (2.7\%), and UTB versus HI (1.8\%). We found that the smallest differences in the offspring were between UTB versus FD, $\mathrm{WB}, \mathrm{WI}$ and between FD versus WB (between $0.1 \%$ and $0.8 \%$ significant Cs). Similar to the data set for the maternal trees, most of the annotated DMPs between populations in the offspring were located in genes $(27 \%$ on average vs. $1 \%$ of DMPs in both repeats and transposons), and the number of DMPs tended to be higher in the CHH context (Table S10). Comparing family pairs in the offspring resulted in between $0.4 \%$ and $14.7 \%$ significant Cs. On average, family pairs differed significantly in $3.3 \%$ of all cytosines. We found the greatest differences between family WB6 and all other 23 families (between $10.2 \%$ and $14.7 \%$ significant Cs; Table S10). We listed gene annotations of these DMPs in Tables S11-S13.

We detected individual fragments in which the epigenetic variation was unlinked to sequence variation on the same reference fragment (i.e., in close-cis). In the maternal trees, we found that population and its interaction with the sequence context (POP \& CTXT:POP) could explain differences in DNA methylation in $19.3 \%$ of all fragments (FDR < 0.05$)$. However, if the terms testing for population were fitted after the factor accounting for the sequence of the fragments (GENO \& CTXT:GENO), only $5.9 \%$ of all fragments were still significant for POP \& CTXT:POP indicating that differences in these fragments could not be explained by the underlying sequence differences in close-cis. In the offspring, POP \& CTXT:POP was significant for $82.7 \%$ of all fragments if fitted first. In addition, terms testing for differences between families (MOTHER \& CTXT:MOTHER) were also significant for $68.2 \%$ of all fragments. Notably, even if GENO \& CTXT:GENO was fitted first, POP \& CTXT:POP and MOTHER \& CTXT:MOTHER were significant in $60.5 \%$ and $45.8 \%$ of all fragments, respectively.

\section{4 | DISCUSSION}

Conservation biologists strive to preserve biodiversity and face the enduring challenge of doing so in the context of changing environmental conditions. While the capacity to respond to environmental challenges ultimately relies on phenotypic variation, deciphering the mechanisms that contribute to phenotypic variation is a challenging task that requires a better understanding of the complex interactions of genetic and nongenetic mechanisms. DNA methylation has been associated with regulation of gene expression (and therefore phenotype) in some contexts, and has been proposed to contribute to phenotypic variation, particularly in populations with low genetic diversity (Douhovnikoff \& Dodd, 2015; Mounger et al., 2021; Richards et al., 2017; Verhoeven \& Preite, 2014). Investigating biodiversity at these different molecular levels can contribute to our understanding of response in foundation species like mangroves, which inhabit dynamic coastal landscapes and are constantly under threat from various anthropogenic challenges. 
(a)

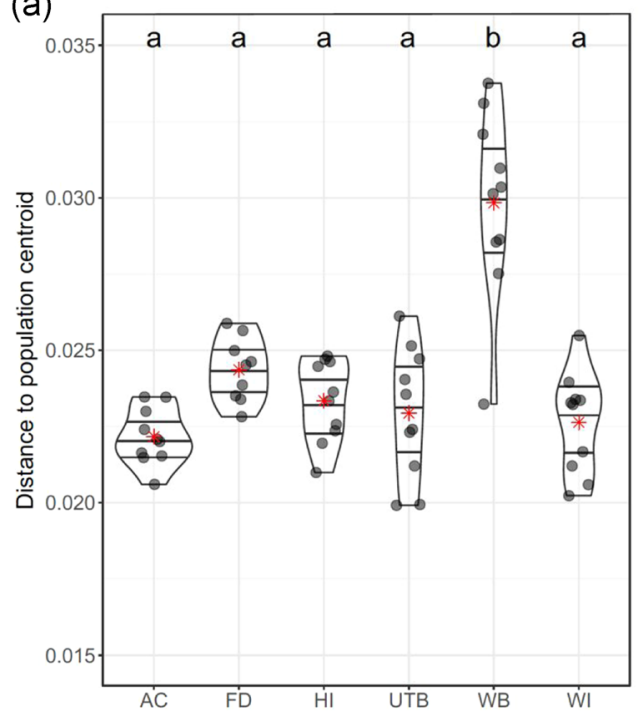

(b)

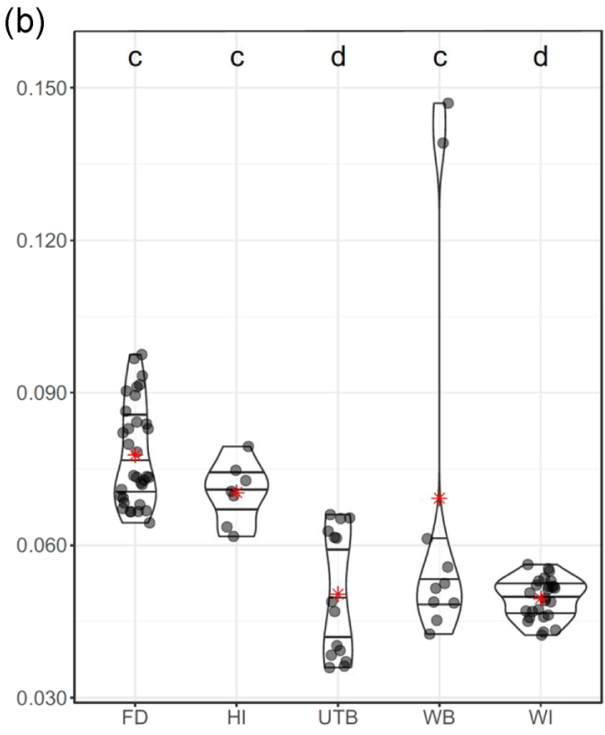

F I G U RE 4 Distance from each individual sample to its corresponding population centroid calculated using epigenetic distance matrices for the maternal trees (a) and offspring datasets (b). Lines within the violin plots mark the 25\%, 50,\% and 75\% quartiles of the distribution; letters inside the graphs summarize the results of the multiple pairwise comparisons where populations sharing letters do not differ significantly in epigenetic diversity; red stars: average distance to centroid for each population [Color figure can be viewed at wileyonlinelibrary.com]

While most mangrove species are not considered to be threatened, habitat loss continues to be a serious threat, with current average annual rates of loss of $1 \%-2 \%$ (Alongi, 2008; Polidoro et al., 2010; Triest et al., 2021). The resultant loss of diversity could pose risks for these coastal foundation species in the future, particularly as sea levels are projected to rise between 0.2 and $2 \mathrm{~m}$ over the next century due to anthropogenic climate change (Melillo et al., 2014). Populations of R. mangle around Tampa Bay are near the species northern limit, dictated largely by periodic freezing events (Kennedy et al., 2017). In addition, they could be more vulnerable to changing conditions due to increased isolation and reduced genetic diversity resulting from inbreeding, limitations in dispersal ability, and increased environmental pressures (Kennedy et al., 2017; Polidoro et al., 2010; SandovalCastro et al., 2012). Our study confirmed that these populations had low genetic diversity, but we also found that differences among populations explained very little of the variation. In fact, genetic diversity was so low that we were unable to accurately estimate inbreeding (i.e., this requires at least 1000 highly polymorphic markers according to Goudet et al. (2018). Although it is difficult to compare absolute levels of epigenetic to genetic variation, there was significant epigenetic variation. Differences among populations explained more of the variation in epigenetic variation than genetic variation for both the maternal trees and offspring. Maternal family explained the largest percentage of the variation in epigenetic variation in the offspring plants. This pattern of DNA methylation in the offspring plants suggests that propagules maintain some level of epigenetic variation inherited from the maternal plant or maternal environment even when they are grown under common garden conditions, which could have important implications for how these propagules can respond to environmental challenges.

\section{1 | Red mangrove population genetics}

High levels of diversity in both heterozygosity and allelic number have been reported from populations of $R$. mangle along the Pacific coast of Nicaragua (Bruschi et al., 2014), and Colombia (Arbeláez-Cortes et al., 2007). However, Pil et al. (2011) determined that genetic diversity was lower in Brazil. They also found considerable genetic structuring between the northern and southern Brazilian populations, possibly resulting from the last glacial period (Pil et al., 2011). Studies at the current range edge have also reported much lower levels of diversity (Kennedy et al., 2017; Polidoro et al., 2010; Sandoval-Castro et al., 2012). In our study, we found overall low levels of diversity, and that most of the genetic variation was found within populations and even more so within families. This type of genetic structure follows from the known levels of inbreeding of the species followed by some mixing of the populations through the limited dispersal of propagules (Francisco et al., 2018; 
Pil et al., 2011). Although differences among populations explained very little of the genetic variation, almost all pairwise comparisons showed significant fine scale genetic differentiation except for the AC to HI and UTB to WI comparisons. The lack of differentiation specifically between these pairs of populations might be explained by spatial proximity and propagule dispersal. UTB and WI are the only two populations sampled that are within the mouth of the bay. AC and HI are both barrier islands that are geographically close to one another and therefore have a conceivably greater chance for dispersal between these two islands than between other populations.

A study by Albrecht et al. (2013) provides insight for interpreting our findings in the context of the larger range of the species, since they compared genetic diversity among Florida and Caribbean populations. They found high genetic structuring among the populations, and that populations from the Gulf Coast of Florida had much higher structuring compared to those along the Atlantic Coast, suggesting that there is limited gene flow along the Gulf Coast and across to other parts of the species range, including the Caribbean islands and throughout Florida (Albrecht et al., 2013). They suggest that genetic structuring and loss of genetic diversity in some populations are related to habitat loss via human development (e.g., the Atlantic Coast of Florida has experienced more extensive habitat loss than the Gulf Coast). While our findings of minimal genetic diversity among populations run contrary to those in Albrecht et al. (2013), this could in part be explained by significant urbanization and resultant habitat loss in the Tampa Bay region. Habitat shifts from Spartina alternifloradominated salt marshes to mangrove forests followed early 20th century anthropogenic activities such as dredging and mosquito ditching in the region (Jackson et al., 2021. These events may also partially explain our findings as founder effects could have accompanied recent mangrove colonization.

Our findings of limited genetic variation in $R$. mangle are similar to other studies in this part of the species range, but contrast with several other foundation coastal species of the southeastern USA., which are outcrossing grasses or rushes that exhibit much higher levels of genetic diversity. Studies on native southeastern US $S$. alterniflora populations have reported diversity levels that are comparable to other outcrossing grasses, despite the fact that this species also spreads prolifically by clonal reproduction (Foust et al., 2016; Richards et al., 2004; Robertson et al., 2017; Zerebecki et al., 2021). Tumas et al. (2019) found greater genetic diversity in Gulf of Mexico than Atlantic coast populations of the salt marsh dominant (potential foundation species) plant Juncus roemerianus, but like in $R$. mangle, measures of genetic diversity varied dramatically across the range. The authors suggest this could be the result of differences in plant community and disturbance regimes or reflect a relationship with population size.

\section{2 | Population epigenetics}

The limited genetic diversity in these populations of $R$. mangle might be cause for concern considering the important ecosystem functions provided by this foundation species (Ellison, 2019; Ellison et al., 2005), but what really matters is how the species can maintain phenotypic response to challenging environments. Our common garden studies revealed that these populations maintain extensive variation in traits and variation in response to salinity and nitrogen treatments (Langanke, 2017; Richards et al., 2021). Like in several other studies of coastal foundation species, we found epigenetic variation was high in $R$. mangle (based on test for dispersion; see also Foust et al., 2016; Hardaway et al., 2020; Jueterbock et al., 2020; Lira-Medeiros et al., 2010; Robertson et al., 2017, 2020). Further, this variation was significantly associated with population for both maternal trees and offspring plants, and even more significantly associated with family for the offspring plants. Although using a categorical family term in the analysis does not allow for prescribing effects specifically to the mother's genetic, epigenetic, or other nongenetic contributions to the offspring epigenetic matrix, the family term does represent a holistic contribution from the maternal tree to offspring and in our study explains the largest portion of the variation (approximately $6 \%$ overall and $25 \%$ of the variation in the CG context). This provides some of the first evidence for epigenetic inheritance in a coastal foundation species.

This finding that CG methylation was best explained by maternal tree is somewhat surprising in the framework of findings from other studies. Within A. thaliana and among species, methylation levels vary in all three contexts, but the differences were reported to be the least in CG context, with $\sim 3 \times$ as much variation in $\mathrm{CHG}$, and $\sim 5 \times$ in CHH contexts (Dubin et al., 2015; Niederhuth \& Schmitz, 2017). On the contrary, Schmid et al. (2018) reported that variation was greatest in the $\mathrm{CG}$ context followed by $\mathrm{CHG}$ and $\mathrm{CHH}$ in recombinant inbred lines of the cross between the A. thaliana accessions Cvi and Landsberg. They also reported that differences between selected and ancestral lines were mostly found in CG, which would support the idea that methylation in CG is more heritable (i.e., that $\mathrm{CHG}$ and $\mathrm{CHH}$ are more prone to be reset). CG methylation has long been associated with transcription, and particularly with silencing when 
found in the promoter region or $5^{\prime}$-end of genes (Paun et al., 2019). In some plants, CG methylation is common in exons of genes that are moderately and broadly expressed, and not associated with silencing. Considering the limitations of our RRBS approach, further study and more in depth bisulfite sequencing will be required to link the methylation changes we found to function in $R$. mangle (Paun et al., 2019; Richards et al., 2017).

While it has been established that genetic variation can have considerable effects on epigenetic variation (Becker et al., 2011; Dubin et al., 2015; Sasaki et al., 2019), we found significant epigenetic structure in both maternal trees and offspring that could not be explained by the genetic sequence (i.e., genetic variation in close cis) of the fragments. Instead, population of origin explained more of the variation in DNA methylation than for sequence variation. This finding was true not only in the field collected plants, but also in the propagules grown in a common garden. Several other studies have found that epigenetic patterns that are associated with habitat can persist in common gardens, suggesting that environmentally induced epigenetic differences can be inherited, and contribute to diversity (Richards et al., 2012; Robertson et al., 2020; Xie et al., 2015). However, in our study, we collected the propagules from the field and they had already matured on the maternal plants. Therefore, some important early developmental responses would reflect the maternal environment. Further study is required to truly control for environmental, maternal, and genetic effects which may not be possible in such a long-lived tree species.

These findings suggest that epigenetic variation could contribute to heritable differences in $R$. mangle, but this would depend also on which propagules survive the various stages of selection before establishment in the field. A recent study of propagule recruitment in $R$. mangle at its range edge near Jacksonville, Florida found that just two maternal trees contributed $79 \%$ of propagules that reached branching stage. Propagule survival was higher in populations within the range core compared to the range edge, even though there was a longer propagule development period and greater reproductive output among trees at the range edge (Goldberg \& Heine, 2017). Populations at the range edges could require particular conservation attention since they have been shown to have greater genetic differences among populations and reduced genetic diversity (Kennedy et al., 2017; Polidoro et al., 2010; Sandoval-Castro et al., 2012), which could constrain adaptive potential. In addition, we know very little about the interactions with the microbiome in the species, but microbes have been highlighted as important symbionts in these and other challenging environments (Bowen et al., 2017; Jung et al., 2021). Moreover, a recent study in the Indian River Lagoon system, in St. Lucie County, Florida suggested that bacterial community composition differed among $R$. mangle maternal genotypes but not with genetic diversity (Craig et al., 2020). Increased warming as a consequence of climate change could result in either the relaxation or amplification of some of these biotic and abiotic limitations at range ends (Devaney et al., 2017). So far, very little is known about how this or any coastal foundation species survives the different selection pressures across the various stages of establishment and spread. Variation in these selection pressures will be amplified by the pressures attendant to anthropogenic climate change.

\section{5 | CONCLUSIONS}

The field of conservation biology relies on identifying the capacity of organisms to respond to environmental challenges which ultimately relies on the manifestation of phenotypic variation through complex interactions of genetic and nongenetic mechanisms. We know that documenting the levels and structure of genetic variation is one piece of information that is important for conservation, but how that information is translated into function largely remains an enigma. We have provided another piece of the puzzle for the coastal foundation plant $R$. mangle that epigenetic variation (namely DNA methylation) is inherited and could be an important component of diversity for this species. However, our interpretation of how this variation might be involved is limited due to the small portion of the genome sampled with our RRBS approach and the limited genomic resources (see also Hardaway et al., 2020; McNew et al., 2021; Robertson et al., 2020; van Moorsel et al., 2019). We look forward to the future of integrating novel molecular tools that can probe more deeply into the molecular underpinnings of response, as they will help shed light on the processes of development in the context of climate change.

\section{ACKNOWLEDGMENTS}

We thank Samantha Blonder, Jordan Dollbaum, Maria Nikolopoulos, Shane Palmer, Bradley Biega, Bryan Lotici, Harper Cassidy, Jelena Dosen, Nancy Sheridan, and Dawei Tang for help with field collections, and with the experimental offspring plants in the greenhouse. We thank Stephen Savage and Priscila Magalhães Galdino for help with the epiGBS laboratory work. We thank the Florida Department of Environmental Protection for providing permits for field collection within Florida State Parks. We thank the Coordenação de Aperfeiçoamento 
de Pessoal de Nível Superior (CAPES, 072/2014)— National Science Foundations (NSF, I-REU) bilateral grant for supporting the international research exchange between USF and the Jardim Botânico do Rio de Janeiro in Brazil for JM, SV, MA, and RG. This study was supported by funding from the National Science Foundation (USA) DEB-1419960 and IOS-1556820 (to CLR), Federal Ministry of Education and Research (BMBF; MOPGA Project ID 306055 to CLR), the European Union's Horizon 2020 research and innovation program under the Marie Skłodowska-Curie grant agreement No 704141BryOmics (to MTB), and the Juan de la CiervaIncorporación program from the Spanish Ministry of Science, Innovation and Universities (IJC2018- 035018-I; to MTB). Open Access funding enabled and organized by Projekt DEAL.

\section{CONFLICT OF INTERESTS}

The authors declare that there are no conflict of interests.

\section{AUTHOR CONTRIBUTIONS}

Christina L. Richards, Catarina Fonseca Lira, Jeannie Mounger, Sandy A. Voors, and Marta H. Robertson conceived the study. Christina L. Richards, Jeannie Mounger, M. Teresa Boquete, Marc W. Schmid, Gordon A. Fox, and David B. Lewis designed the experiments and analyses. Jeannie Mounger, Kristen L. Langanke, Sandy A. Voors, Mariano Alvarez, and Marta H. Robertson collected plants and maintained experiments. Jeannie Mounger, Marta H. Robertson, M. Teresa Boquete, Renan Granado, and Cornelis A.M. Wagemaker did the epiGBS laboratory work. M. Teresa Boquete, Marc W. Schmid, and Aaron W. Schrey analyzed the epiGBS data. Christina L. Richards, Jeannie Mounger, M. Teresa Boquete, and Marc W. Schmid wrote the first draft of the manuscript. All co-authors provided input and revisions to the manuscript.

\section{DATA AVAILABILITY STATEMENT}

The pipeline scripts we used for this study are available at: https://github.com/thomasvangurp/epiGBS, with a bug-fix modification (https://github.com/MWSchmid/ epiGBS_Nov_2017_fixed). Raw sequence data files for epiGBS (Illumina reads after demultiplexing) have been submitted to the Sequence Read Archive (SRA) of NCBI under project number PRJNA746695. The barcodes (barcodes.txt) required to process the sequencing data available on SRA, the experimental design (design.txt), the reference contigs (contigs.fasta.gz), the annotation of the reference contigs (mergedAnnot.csv.gz), the SNPs (snps.vcf.gz), the methylation data (methylation.txt.gz), and Table S13 Differential cytosine methylation between families (FDSSwithGeneAnnotation.offspringFams) are all available on zenodo (doi:10.5281/zenodo.5102719). (1) RM_R1_noGBS.fastq.gz and (2) RM_R2_noGBS.fastq.gz: https://www.icloud.com/iclouddrive/0pC7Oykol85_ b4hQ8E66pExmg\#GitIgnore\%5FrawData

\section{ORCID}

Jeannie Mounger (1) https://orcid.org/0000-00024315-3301

M. Teresa Boquete (D) https://orcid.org/0000-00025886-7374

Marc W. Schmid (1) https://orcid.org/0000-0001-

9554-5318

Renan Granado (D) http://orcid.org/0000-0002-6095-4848

Marta H. Robertson (D) https://orcid.org/0000-0003-

0102-4541

Mariano Alvarez (D) https://orcid.org/0000-0002-

9951-0013

Cornelis A.M. Wagemaker (1) https://orcid.org/0000-00028968-4546

Aaron W. Schrey (D) https://orcid.org/0000-0002-

2165-7349

Gordon A. Fox (D) https://orcid.org/0000-0003-0595-1385 David B. Lewis (D) https://orcid.org/0000-0002-8094-1577 Catarina Fonseca Lira (D) http://orcid.org/0000-00018971-4226

Christina L. Richards (D) http://orcid.org/0000-0001-

7848-5165

\section{REFERENCES}

Albrecht, M., Kneeland, K. M., Lindroth, E., \& Foster, J. E. (2013). Genetic diversity and relatedness of the mangrove Rhizophora mangle L. (Rhizophoraceae) using amplified fragment polymorphism (AFLP) among locations in Florida, USA and the Caribbean. Journal of Coastal Conservation, 17, 483-491. https://doi.org/10.1007/s11852-013-0246-3

Allendorf, F. W. A., Luikart, G. H., \& Aitken, S. N. (2012). Conservation and the genetics of populations (2nd ed.). WileyBlackwell.

Alongi, D. M. (2008). Mangrove forests: Resilience, protection from tsunamis, and responses to global climate change. Estuarine, Coastal and Shelf Science, 76, 1-13. https://doi.org/10.1016/j. ecss.2007.08.024

Alonso, C., Ramos-Cruz, D., \& Becker, C. (2019). The role of plant epigenetics in biotic interactions. New Phytologist, 221, 731-737. https://doi.org/10.1111/nph.15408

Anderson, M. J., Ellingsen, K. E., \& McArdle, B. H. (2006). Multivariate dispersion as a measure of beta diversity. Ecology Letters, 9, 683-693. https://doi.org/10.1111/j.1461-0248.2006. 00926.x

Arbeláez-Cortes, E., Castillo-Cárdenas, M. F., Toro-Perea, N., \& Cárdenas-Henao, H. (2007). Genetic structure of the red mangrove (Rhizophora mangle L.) on the Colombian Pacific detected by microsatellite molecular markers. Hydrobiologia, 583, 321-330. https://doi.org/10.1007/s10750-007-0622-9

Balao, F., Paun, O., \& Alonso, C. (2018). Uncovering the contribution of epigenetics to plant phenotypic variation in Mediterranean 
ecosystems. Plant Biology (Stuttgart), 20, 38-49. https://doi.org/ 10.1111/plb.12594

Banta, J. A., \& Richards, C. L. (2018). Quantitative epigenetics and evolution. Heredity, 121, 210-224. https://doi.org/10.1038/ s41437-018-0114-X

Becker, C., Hagmann, J., Müller, J., Koenig, D., Stegle, O., Borgwardt, K., \& Weigel, D. (2011). Spontaneous epigenetic variation in the Arabidopsis thaliana methylome. Nature, 480, 245-249. https://doi.org/10.1038/nature10555

Benjamini, Y., \& Hochberg, Y. (1995). Controlling the false discovery rate: A practical and powerful approach to multiple testing. Journal of the Royal Statistical Society 57, 289-300. https://doi.org/10.1111/j.2517-6161.1995.tb02031.x

Bilichak, A., Ilnytskyy, Y., Wóycicki, R., Kepeshchuk, N., Fogen, D., \& Kovalchuk, I. (2015). The elucidation of stress memory inheritance in Brassica rapa plants. Frontiers of Plant Science, 6, 5. https://doi.org/10.3389/fpls.2015.00005

Björklund, M., Ranta, E., Kaitala, V., Bach, L. A., Lundberg, P., \& Stenseth, N. C. (2009). Quantitative trait evolution and environmental change. PLOS One, 4, e4521. https://doi.org/ 10.1371/journal.pone.0004521

Blevins, T., Pontvianne, F., Cocklin, R., Podicheti, R., Chandrasekhara, C., Yerneni, S., Braun, C., Lee, B., Rusch, D., Mockaitis, K., Tang, H., \& Pikaard, C. S. (2014). A two-step process for epigenetic inheritance in Arabidopsis. Molecular Cell, 54, 30-42. https://doi.org/10.1016/j.molcel.2014.02.019

Bonduriansky, R., \& Day, T. (2018). Extended heredity. Princeton University Press.

Bowen, J. L., Kearns, P. J., Byrnes, J., Wigginton, S., Allen, W. J., Greenwood, M., Tran, K., Yu, J., Cronin, J. T., \& Meyerson, L. A. (2017). Lineage overwhelms environ mental conditions in determining rhizosphere bacterial community structure in a cosmopolitan invasive plant. Nature Communications, 8, 433. https://doi.org/10.1038/ s41467-017-00626-0

Bruschi, P., Angeletti, C., González, O., Adele Signorini, M., \& Bagnoli, F. (2014). Genetic and morphological variation of Rhizophora mangle (red mangrove) along the northern Pacific coast of Nicaragua. Nordic Journal of Botany, 32, 320-329. https://doi.org/10.1111/j.1756-1051.2013.00138.x

Buchfink, B., Xie, C., \& Huson, D. H. (2015). Fast and sensitive protein alignment using DIAMOND. Nature Methods, 12, 59-60. https://doi.org/10.1038/nmeth.3176

Burggren, W. (2016). Epigenetic inheritance and its role in evolutionary biology: Re-evaluation and new perspectives. Biology, 5, 24. https://doi.org/10.3390/biology5020024

Campbell, C. S., Adams, C. E., Bean, C. W., \& Parsons, K. J. (2017). Conservation Evo-devo: Preserving biodiversity by understanding its origins. Trends in Ecology and Evolution (Personal Edition), 32, 746-759. https://doi.org/10.1016/j.tree. 2017.07.002

Cerón-Souza, I., Bermingham, E., McMillan, W. O., \& Jones, F. A. (2012). Comparative genetic structure of two mangrove species in Caribbean and Pacific estuaries of Panama. BMC Evolutionary Biology, 12, 205. https://doi.org/10.1186/14712148-12-205

Cerón-Souza, I., Rivera-Ocasio, E., Medina, E., Jiménez, J. A., McMillan, W. O., \& Bermingham, E. (2010). Hybridization and introgression in New World red mangroves, Rhizophora
(Rhizophoraceae). American Journal of Botany, 97, 945-957. https://doi.org/10.3732/ajb.0900172

Chablé Iuit, L. R., Machkour-M'Rabet, S., Espinoza-Ávalos, J., Hernández-Arana, H. A., López-Adame, H., \& Hénaut, Y. (2020). Genetic structure and connectivity of the red mangrove at different geographic scales through a complex transverse hydrological system from freshwater to marine ecosystems. Diversity (Basel), 12, 48. https://doi.org/10.3390/ d12020048

Chen, C., Zheng, Z., Bao, Y., Zhang, H., Richards, C. L., Li, J., Chen, Y., Zhao, Y., Shen, Z., \& Fu, C. (2020). Comparisons of natural and cultivated populations of Corydalis yanhusuo indicate divergent patterns of genetic and epigenetic variation. Frontiers of Plant Science, 11, 985. https://doi.org/10.3389/fpls. 2020.00985

Cortijo, S., Wardenaar, R., Colomé-Tatché, M., Gilly, A., Etcheverry, M., Labadie, K., Caillieux, E., Hospital, F., Aury, J. M., Wincker, P., Roudier, F., Jansen, R. C., Colot, V., \& Johannes, F. (2014). Mapping the epigenetic basis of complex traits. Science, 343, 1145-1148. https://doi.org/10. 1126/science.1248127

Craig, H., Kennedy, J. P., Devlin, D. J., Bardgett, R. D., \& Rowntree, J. K. (2020). Effects of maternal genotypic identity and genetic diversity of the red mangrove Rhizophora mangle on associated soil bacterial communities: A field-based experiment. Ecology and Evolution, 10, 13957-13967. https:// doi.org/10.1002/ece3.6989

De Kort, H., Panis, B., Deforce, D., Van Nieuwerburgh, F., \& Honnay, O. (2020). Ecological divergence of wild strawberry DNA methylation patterns at distinct spatial scales. Molecular Ecology, 29, 4871-4881. https://doi.org/10.1111/mec.15689

Devaney, J. L., Lehmann, M., Feller, I. C., \& Parker, J. D. (2017). Mangrove microclimates alter seedling dynamics at the range edge. Ecology, 98, 2513-2520. https://doi.org/10.1002/ecy.1979

DeYoe, H., Lonard, R. I., Judd, F. W., Stalter, R., \& Feller, I. (2020). Biological flora of the tropical and subtropical intertidal zone: Literature review for Rhizophora mangle L. Journal of Coastal Research, 36, 857. https://doi.org/10.2112/jcoastres-d19-00088.1

Dodd, R. S., \& Douhovnikoff, V. (2016). Adjusting to global change through clonal growth and epigenetic variation. Frontiers in Ecology and Evolution, 4, 86. https://doi.org/10.3389/fevo. 2016.00086

Donat, H. (2011). A blueprint for blue carbon: Toward an improved understanding of the role of vegetated coastal habitats in sequestering CO2. Frontiers in Ecology and the Environment, 9, 552-560. https://doi.org/10.1890/110004

Douhovnikoff, V., \& Dodd, R. S. (2015). Epigenetics: A potential mechanism for clonal plant success. Plant Ecology, 216, 227-233. https://doi.org/10.1007/s11258-014-0430-z

Dowen, R. H., Pelizzola, M., Schmitz, R. J., Lister, R., Dowen, J. M., Nery, J. R., Dixon, J. E., \& Ecker, J. R. (2012). Widespread dynamic DNA methylation in response to biotic stress. Proceedings of the National Academy of Sciences of the United States of America, 109, E2183-E2191. https://doi.org/ 10.1073/pnas.1209329109

Dray, S., \& Dufour, A.-B. (2007). Theade4Package: Implementing the duality diagram for ecologists. Journal of Statistical Software, 22, 22. https://doi.org/10.18637/jss.v022.i04 
Dubin, M. J., Zhang, P., Meng, D., Remigereau, M.-S., Osborne, E. J., Paolo Casale, F., Drewe, P., Kahles, A., Jean, G., Vilhjálmsson, B., Jagoda, J., Irez, S., Voronin, V., Song, Q., Long, Q., Rätsch, G., Stegle, O., Clark, R. M., \& Nordborg, M. (2015). DNA methylation in Arabidopsis has a genetic basis and shows evidence of local adaptation. eLife, 4, e05255. https://doi.org/10.7554/eLife.05255

Duke, N. C., Lo, E., \& Sun, M. (2002). Global distribution and genetic discontinuities of mangroves-Emerging patterns in the evolution of Rhizophora. Trees (Berl. West), 16, 65-79. https://doi.org/10.1007/s00468-001-0141-7

Ellison, A., Farnsworth, E., \& Moore, G. (2015). Rhizophora mangle. IUCN Red List of Threatened Species, 55, 1179-1186. https://doi.org/10.2305/iucn.uk.2015-1.rlts.t178851a69024847. en

Ellison, A. M. (2019). Foundation species, non-trophic interactions, and the value of being common. iScience, 13, 254-268. https:// doi.org/10.1016/j.isci.2019.02.020

Ellison, A. M., Bank, M. S., Clinton, B. D., Colburn, E. A., Elliott, K., Ford, C. R., Foster, D. R., Kloeppel, B. D., Knoepp, J. D., Lovett, G. M., Mohan, J., Orwig, D. A., Rodenhouse, N. L., Sobczak, W. V., Stinson, K. A., Stone, J. K., Swan, C. M., Thompson, J., Von Holle, B., \& Webster, J. R. (2005). Loss of foundation species: Consequences for the structure and dynamics of forested ecosystems. Frontiers in Ecology and the Environment, 3, 479-486. https://doi.org/10. 1890/1540-9295(2005)003[0479:1ofscf]2.0.c0;2

Fischer, M. C., Foll, M., Excoffier, L., \& Heckel, G. (2011). Enhanced AFLP genome scans detect local adaptation in highaltitude populations of a small rodent (Microtus arvalis). Molecular Ecology, 20, 1450-1462. https://doi.org/10.1111/j. 1365-294x.2011.05015.x

Foll, M., \& Gaggiotti, O. (2008). A genome-scan method to identify selected loci appropriate for both dominant and codominant markers: A Bayesian perspective. Genetics, 180, 977-993. https://doi.org/10.1534/genetics.108.092221

Foust, C. M., Preite, V., Schrey, A. W., Alvarez, M., Robertson, M. H., Verhoeven, K. J., \& Richards, C. L. (2016). Genetic and epigenetic differences associated with environmental gradients in replicate populations of two salt marsh perennials. Molecular Ecology, 25, 1639-1652. https:// doi.org/10.1111/mec.13522

Francisco, P. M., Mori, G. M., Alves, F. M., Tambarussi, E. V., \& de Souza, A. P. (2018). Population genetic structure, introgression, and hybridization in the genus Rhizophora along the Brazilian coast. Ecology and Evolution, 8, 3491-3504. https://doi.org/10.1002/ece3.3900

Gawehns, F., Postuma, M., van Gurp, T. P., Wagemaker, C. A. M., Fatma, S., Van Antro, M., Mateman, C., Milanovic-Ivanovic, S., van Oers, K., Grosse, I., Vergeer, P., \& Verhoeven, K. J. F. (2020). epiGBS2: An improved protocol and automated snakemake workflow for highly multiplexed reduced representation bisulfite sequencing. bioRxiv. https://doi.org/ 10.1101/2020.06.23.137091

Godoy, M. D. P., \& de Lacerda, L. D. (2015). Mangroves response to climate change: A review of recent findings on mangrove extension and distribution. Anais da Academia Brasileira de Ciencias, 87, 651-667. https://doi.org/10.1590/0001-3765 201520150055
Goldberg, N. A., \& Heine, J. N. (2017). Life on the leading edge: Phenology and demography of the red mangrove Rhizophora mangle L. at the northern limit of its expanding range. Flora, 235, 76-82. https://doi.org/10.1016/j.flora.2017.09.003

Goudet, J. (2005). hierfstat, a package for $r$ to compute and test hierarchical F-statistics. Molecular Ecology Notes, 5, 184-186. https://doi.org/10.1111/j.1471-8286.2004.00828.x

Goudet, J., Kay, T., \& Weir, B. S. (2018). How to estimate kinship. Molecular Ecology, 27, 4121-4135. https://doi.org/10.1111/ mec.14833

Guo, S. W., \& Thompson, E. A. (1992). Performing the exact test of Hardy-Weinberg proportion for multiple alleles. Biometrics, 48, 361-372. https://doi.org/10.2307/2532296

Gáspár, B., Bossdorf, O., \& Durka, W. (2019). Structure, stability and ecological significance of natural epigenetic variation: A large-scale survey in Plantago lanceolata. New Phytologist, 221, 1585-1596. https://doi.org/10.1111/nph.15487

Hardaway, R. M., Dumke, R., Gee, T., Meyers, T., Joyner, J., Graf, J., Lee, D., \& Revels, J. (2020). Reduced representation characterization of genetic and epigenetic differentiation to oil pollution in the foundation plant Spartina alterniflora. bioRxiv, 189, 373-376. https://doi.org/10.1101/426569

Henn, J. J., Buzzard, V., Enquist, B. J., Halbritter, A. H., Klanderud, K., Maitner, B. S., Michaletz, S. T., Pötsch, C., Seltzer, L., Telford, R. J., Yang, Y., Zhang, L., \& Vandvik, V. (2018). Intraspecific trait variation and phenotypic plasticity mediate alpine plant species response to climate change. Frontiers of Plant Science, 9, 1548. https://doi.org/10.3389/fpls. 2018.01548

Herman, J. J., \& Sultan, S. E. (2016). DNA methylation mediates genetic variation for adaptive transgenerational plasticity. Proceedings of the Royal Society B: Biological Sciences, 283, 283. https://doi.org/10.1098/rspb.2016.0988

Herrera, C. M., \& Bazaga, P. (2011). Untangling individual variation in natural populations: Ecological, genetic and epigenetic correlates of long-term inequality in herbivory. Molecular Ecology, 20, 1675-1688. https://doi.org/10.1111/j. 1365-294X.2011.05026.x

Herrera, C. M., Medrano, M., \& Bazaga, P. (2017). Comparative epigenetic and genetic spatial structure of the perennial herb Helleborus foetidus: Isolation by environment, isolation by distance, and functional trait divergence. American Journal of Botany, 104, 1195-1204. https://doi.org/10.3732/ajb.1700162

Hufford, K. M., \& Mazer, S. J. (2003). Plant ecotypes: Genetic differentiation in the age of ecological restoration. Trends in Ecology and Evolution (Personal Edition), 18, 147-155. https:// doi.org/10.1016/s0169-5347(03)00002-8

Jackson, K., Brooks, G. R., Larson, R. A. (2021). Of marsh and mangrove: coupled biophysical and anthropogenic drivers of 20th century wetland conversion in Tampa Bay Estuary, Florida (USA). Anthropocene, 34, 100295. http://dx.doi.org/10. 1016/j.ancene.2021.100295

Jombart, T. (2008). adegenet: A R package for the multivariate analysis of genetic markers. Bioinformatics, 24, 1403-1405. https://doi.org/10.1093/bioinformatics/btn129

Jueterbock, A., Boström, C., Coyer, J. A., Olsen, J. L., Kopp, M., Dhanasiri, A., Smolina, I., Arnaud-Haond, S., Van de Peer, Y., \& Hoarau, G. (2020). The seagrass methylome is associated with variation in photosynthetic performance among clonal 
shoots. Frontiers of Plant Science, 11, 571646. https://doi.org/ 10.3389/fpls.2020.571646

Jung, J.-H., Reis, F., Richards, C., \& Bossdorf, O. (2021). Understanding plant microbiomes requires a $G \times$ framework. EcoEvoRxiv. https://doi.org/10.32942/osf.io/bvpyc

Kamvar, Z. N., Tabima, J. F., \& Grünwald, N. J. (2014). Poppr: An R package for genetic analysis of populations with clonal, partially clonal, and/or sexual reproduction. PeerJ, 2, e281. https://doi.org/10.7717/peerj.281

Kawakatsu, T., Huang, S. C., Jupe, F., Sasaki, E., Schmitz, R. J., Urich, M. A., Castanon, R., Nery, J. R., Barragan, C., He, Y., Chen, H., Dubin, M., Lee, C. R., Wang, C., Bemm, F., Becker, C., O'Neil, R., O'Malley, R. C., Quarless, D. X., ... Ecker, J. R. (2016). Epigenomic diversity in a global collection of Arabidopsis thaliana accessions. Cell, 166, 492-505. https:// doi.org/10.1016/j.cell.2016.06.044

Keith, A. R., Bailey, J. K., Lau, M. K., \& Whitham, T. G. (2017). Genetics-based interactions of foundation species affect community diversity, stability and network structure. Proceedings. Biological sciences/The Royal Society, 284, 284. https://doi.org/10.1098/rspb.2016.2703

Keller, E. F. (2002). The century of the gene. Harvard University Press. https://play.google.com/store/books/details?id=N6gomAEACAAJ

Keller, E. F. (2014). From gene action to reactive genomes. Journal of Physiology, 592, 2423-2429. https://doi.org/10.1113/jphysi ol.2014.270991

Kennedy, J. P., Garavelli, L., Truelove, N. K., Devlin, D. J., Box, S. J., Chérubin, L. M., \& Feller, I. C. (2017). Contrasting genetic effects of red mangrove (Rhizophora mangleL.) range expansion along West and East Florida. Journal of Biogeography 44, 335-347. https://doi.org/10.1111/jbi.12813

Langanke, K. L. (2017). Response to nitrogen and salinity conditions in Rhizophora mangle seedlings varies by site of origin. https://scholarcommons.usf.edu/etd/7048

Lang-Mladek, C., Popova, O., Kiok, K., Berlinger, M., Rakic, B., Aufsatz, W., Jonak, C., Hauser, M. T., \& Luschnig, C. (2010). Transgenerational inheritance and resetting of stress-induced loss of epigenetic gene silencing in Arabidopsis. Molecular Plant, 3, 594-602. https://doi.org/10.1093/mp/ssq014

Li, Q., Eichten, S. R., Hermanson, P. J., \& Springer, N. M. (2014). Inheritance patterns and stability of DNA methylation variation in maize near-isogenic lines. Genetics, 196, 667-676. https://doi. org/10.1534/genetics.113.158980

Lira-Medeiros, C. F., Parisod, C., Fernandes, R. A., Mata, C. S., Cardoso, M. A., \& Ferreira, P. C. G. (2010). Epigenetic variation in mangrove plants occurring in contrasting natural environment. PLOS One, 5, e10326. https://doi.org/10.1371/ journal.pone.0010326

McNew, S. M., Boquete, M. T., Espinoza-Ulloa, S., Andres, J. A., Wagemaker, N., Knutie, S. A., Richards, C. L., \& Clayton, D. H. (2021). Epigenetic effects of parasites and pesticides on captive and wild nestling birds. Ecology and Evolution, 11, 7713-7729. https://doi.org/10.1002/ece3.7606

Medrano, M., Herrera, C. M., \& Bazaga, P. (2014). Epigenetic variation predicts regional and local intraspecific functional diversity in a perennial herb. Molecular Ecology, 23, 4926-4938. https://doi.org/10.1111/mec.12911

J. M. Melillo, T.T.C. Richmond, \& G. W. Yohe (Eds.). (2014). Climate change impacts in the United States: The third national climate assessment. U.S. Global Change Research Program. https://doi.org/10.7930/j0z31wj2

Mounger, J., Ainouche, M. L., Bossdorf, O., Cavé-Radet, A., Li, B., Parepa, M., Salmon, A., Yang, J., \& Richards, C. L. (2021). Epigenetics and the success of invasive plants. Philosophical Transactions Royal Society B, 376, 20200117. https://doi.org/ 10.1098/rstb.2020.0117

Nadia, T. L., \& Machado, I. C. (2014). Wind pollination and propagule formation in Rhizophora mangle L. (Rhizophoraceae): Resource or pollination limitation? Anais da Academia Brasileira de Ciencias, 86, 229-238. https://doi. org/10.1590/0001-37652014101712

Nei, M. (1987). Molecular evolutionary genetics. Columbia University Press. https://doi.org/10.7312/nei-92038

Neinavaie, F., Ibrahim Hashim, A., Kramer, A. M., Brown, J. S. \& Richards, C. L. (2021). The genomic processes of biological invasions: From invasive species to cancer metastases and back again. Front. Ecol. Evol. 10.3389/fevo.2021.681100.

Nicotra, A. B., Segal, D. L., Hoyle, G. L., Schrey, A. W., Verhoeven, K. J. F., \& Richards, C. L. (2015). Adaptive plasticity and epigenetic variation in response to warming in an Alpine plant. Ecology and Evolution, 5, 634-647. https:// doi.org/10.1002/ece3.1329

Niederhuth, C. E., \& Schmitz, R. J. (2017). Putting DNA methylation in context: From genomes to gene expression in plants. Biochimica et Biophysica Acta, Gene Regulatory Mechanisms, 1860, 149-156. https://doi.org/10.1016/j.bbagrm. 2016.08.009

Norberg, J., Swaney, D. P., Dushoff, J., Lin, J., Casagrandi, R., \& Levin, S. A. (2001). Phenotypic diversity and ecosystem functioning in changing environments: A theoretical framework. Proceedings of the National Academy of Sciences of the United States of America, 98, 11376-11381. https://doi. org/10.1073/pnas.171315998

Oksanen, J., Blanchet, F. G., Friendly, M., Kindt, R., Legendre, P., Minchin, P. R., O'Hara, R. B., Simpson, G. L., Solymos, P., Henry, M., Stevens, H., \& Wagner, H. (2017). Vegan: Community ecology package. $\mathrm{R}$ package version 2.4-4. https://CRAN.R-project.org/package=vegan

Osland, M. J., Day, R. H., Hall, C. T., Brumfield, M. D., Dugas, J. L., \& Jones, W. R. (2017). Mangrove expansion and contraction at a poleward range limit: Climate extremes and land-ocean temperature gradients. Ecology, 98, 125-137. https://doi.org/ 10.1002/ecy.1625

Osland, M. J., Enwright, N., Day, R. H., \& Doyle, T. W. (2013). Winter climate change and coastal wetland foundation species: Salt marshes vs. mangrove forests in the southeastern United States. Global Change Biology 19, 1482-1494. https://doi.org/10.1111/gcb.12126

Osland, M. J., Griffith, K. T., Larriviere, J. C., Feher, L. C., Cahoon, D. R., Enwright, N. M., Oster, D. A., Tirpak, J. M., Woodrey, M. S., Collini, R. C., Baustian, J. J., Breithaupt, J. L., Cherry, J. A., Conrad, J. R., Cormier, N., Coronado-Molina, C. A., Donoghue, J. F., Graham, S. A., Harper, J. W., ... Wilson, K. V. (2017). Assessing coastal wetland vulnerability to sea-level rise along the northern Gulf of Mexico coast: Gaps and opportunities for developing a coordinated regional sampling network. PLOS One, 12, e0183431. https://doi.org/ 10.1371/journal.pone.0183431 
Paradis, E. (2010). pegas: An R package for population genetics with an integrated-modular approach. Bioinformatics, 26, 419-420. https://doi.org/10.1093/bioinformatics/btp696

Park, Y., \& Wu, H. (2016). Differential methylation analysis for BSseq data under general experimental design. Bioinformatics, 32, 1446-1453. https://doi.org/10.1093/bioinformatics/btw026

Paun, O., Verhoeven, K. J. F., \& Richards, C. L. (2019). Opportunities and limitations of reduced representation bisulfite sequencing in plant ecological epigenomics. New Phytologist, 221, 738-742. https://doi.org/10.1111/nph.15388

Pigliucci, M. (2010). Genotype-phenotype mapping and the end of the "genes as blueprint" metaphor. Philosophical Transactions of the Royal Society of London. Series B, Biological Sciences, 365, 557-566. https://doi.org/10.1098/rstb.2009.0241

Pil, M. W., Boeger, M. R. T., Muschner, V. C., Pie, M. R., Ostrensky, A., \& Boeger, W. A. (2011). Postglacial northsouth expansion of populations of Rhizophora mangle (Rhizophoraceae) along the Brazilian coast revealed by microsatellite analysis. American Journal of Botany, 98, 1031-1039. https://doi.org/10.3732/ajb.1000392

Polidoro, B. A., Carpenter, K. E., Collins, L., Duke, N. C., Ellison, A. M., Ellison, J. C., Farnsworth, E. J., Fernando, E. S., Kathiresan, K., Koedam, N. E., Livingstone, S. R., Miyagi, T., Moore, G. E., Ngoc Nam, V., Ong, J. E., Primavera, J. H., Salmo, S. G., Sanciangco, J. C., Sukardjo, S., ... Yong, J. W. (2010). The loss of species: Mangrove extinction risk and geographic areas of global concern. PLOS One, 5, e10095. https://doi.org/10.1371/journal.pone.0010095

Proffitt, C. E., \& Travis, S. (2014). Red mangrove life history variables along latitudinal and anthropogenic stress gradients. Ecology and Evolution, 4, 2352-2359. https://doi.org/10.1002/ ece3.1095

Proffitt, C. E., \& Travis, S. E. (2005). Albino mutation rates in red mangroves (Rhizophora mangle L.) as a bioassay of contamination history in Tampa Bay, Florida, USA. Wetlands (Wilmington), 25, 326-334. https://doi.org/10.1672/9

Puy, J., Carmona, C. P., Dvořáková, H., Latzel, V., \& de Bello, F. (2021). Diversity of parental environments increases phenotypic variation in Arabidopsis populations more than genetic diversity but similarly affects productivity. Annali di Botanica, 127, 425-436. https://doi.org/10.1093/aob/mcaa100

Puy, J., de Bello, F., Dvořáková, H., Medina, N. G., Latzel, V., \& Carmona, C. P. (2021). Competition-induced transgenerational plasticity influences competitive interactions and leaf decomposition of offspring. New Phytologist, 229, 3497-3507. https://doi.org/10.1111/nph.17037

Qiao, X., Zhang, J., Wang, Z., Xu, Y., Zhou, T., Mi, X., Cao, M., Ye, W., Jin, G., Hao, Z., Wang, X., Wang, X., Tian, S., Li, X., Xiang, W., Liu, Y., Shao, Y., Xu, K., Sang, W., ... Ellison, A. M. (2021). Foundation species across a latitudinal gradient in China. Ecology, 102, e03234. https://doi.org/10.1002/ecy.3234

Rabinowitz, D. (1978). Mortality and initial propagule size in mangrove seedlings in Panama. Journal of Ecology, 66, 45. https://doi.org/10.2307/2259180

R Core Team. (2020). A language and environment for statistical computing. Austria: R Foundation for Statistical Computing Available at: https://www.R-project.org/

Richards, C. L., Alonso, C., Becker, C., Bossdorf, O., Bucher, E., Colomé-Tatché, M., Durka, W., Engelhardt, J., Gaspar, B.,
Gogol-Döring, A., Grosse, I., van Gurp, T. P., Heer, K., Kronholm, I., Lampei, C., Latzel, V., Mirouze, M., Opgenoorth, L., Paun, O., ... Verhoeven, K. (2017). Ecological plant epigenetics: Evidence from model and non-model species, and the way forward. Ecology Letters, 20, 1576-1590. https://doi.org/10.1111/ele.12858

Richards, C. L., Hamrick, J. L., \& Donovan, L. A. (2004). Unexpectedly high clonal diversity of two salt marsh perennials across a severe environmental gradient. Ecology Letters, 2004(7), 1155-1162. https://doi.org/10.1111/j.1461-0248.2004.00674.x

Richards, C. L., Langanke, K. L., Mounger, J., Fox, G. A., \& Lewis, D. B. (2021). Response to nitrogen and salinity conditions in Rhizophora mangle seedlings varies by site of origin. BioRxiv. https://doi.org/10.1101/2021.08.04.454989

Richards, C. L., \& Pigliucci, M. (2020). Epigenetic inheritance a decade into the extended evolutionary synthesis. Paradigmi, 38, 463-494. https://doi.org/10.30460/99624

Richards, C. L., Schrey, A. W., \& Pigliucci, M. (2012). Invasion of diverse habitats by few Japanese knotweed genotypes is correlated with epigenetic differentiation. Ecology Letters, 15, 1016-1025. https://doi.org/10.1111/j.1461-0248.2012.01824.x

Robertson, M., Alvarez, M., van Gurp, T., Wagemaker, C. A. M., Yu, F., Amador, D. M., Farmerie, W. G., Verhoeven, K. J. F., \& Richards, C. L. (2020). Combining epiGBS markers with long read transcriptome sequencing to assess differentiation associated with habitat in Reynoutria (aka Fallopia). bioRxiv. https://doi.org/10.1101/2020.09.30.317966

Robertson, M., Schrey, A., Shayter, A., Moss, C. J., \& Richards, C. (2017). Genetic and epigenetic variation in Spartina alterniflora following the Deepwater Horizon oil spill. Evolutionary Applications, 10, 792-801. https://doi.org/10. 1111/eva.12482

Salmon, A., Ainouche, M. L., \& Wendel, J. F. (2005). Genetic and epigenetic consequences of recent hybridization and polyploidy in Spartina (Poaceae). Molecular Ecology, 14, 1163-1175. https://doi.org/10.1111/j.1365-294X.2005.02488.x

Sandoval-Castro, E., Muñiz-Salazar, R., Enríquez-Paredes, L. M., Riosmena-Rodríguez, R., Dodd, R. S., Tovilla-Hernández, C., \& Arredondo-García, M. C. (2012). Genetic population structure of red mangrove (Rhizophora mangle L.) along the northwestern coast of Mexico. Aquatic Botany, 99, 20-26. https://doi.org/10.1016/j.aquabot.2012.01.002

Sasaki, E., Kawakatsu, T., Ecker, J. R., \& Nordborg, M. (2019). Common alleles of CMT2 and NRPE1 are major determinants of $\mathrm{CHH}$ methylation variation in Arabidopsis thaliana. PLOS Genetics, 15, e1008492. https://doi.org/10.1371/journal.pgen. 1008492

Schmid, M. W., Heichinger, C., Coman Schmid, D., Guthörl, D., Gagliardini, V., Bruggmann, R., Aluri, S., Aquino, C., Schmid, B., Turnbull, L. A., \& Grossniklaus, U. (2018). Contribution of epigenetic variation to adaptation in Arabidopsis. Nature Communications, 9, 4446. https://doi. org/10.1038/s41467-018-06932-5

Schuerch, M., Spencer, T., Temmerman, S., Kirwan, M. L., Wolff, C., Lincke, D., McOwen, C. J., Pickering, M. D., Reef, R., Vafeidis, A. T., Hinkel, J., Nicholls, R. J., \& Brown, S. (2018). Future response of global coastal wetlands to sea-level rise. Nature, 561, 231-234. https://doi.org/10.1038/s41586-0180476-5 
Schulz, B., Eckstein, R. L., \& Durka, W. (2014). Epigenetic variation reflects dynamic habitat conditions in a rare floodplain herb. Molecular Ecology, 23, 3523-3537. https://doi.org/10.1111/ mec.12835

Sehrish, T., Symonds, V. V., Soltis, D. E., Soltis, P. S., \& Tate, J. A. (2014). Gene silencing via DNA methylation in naturally occurring Tragopogon miscellus (Asteraceae) allopolyploids. BMC Genomics, 15, 701. https://doi.org/10.1186/1471-216415-701

Sengupta, R., Middleton, B., Yan, C., Zuro, M., \& Hartman, H. (2005). Landscape characteristics of Rhizophora mangle forests and propagule deposition in coastal environments of Florida (USA). Landscape Ecology, 20, 63-72. https://doi.org/ 10.1007/s10980-004-0468-8

Shi, W., Chen, X., Gao, L., Xu, C.-Y., Ou, X., Bossdorf, O., Yang, J., \& Geng, Y. (2018). Transient stability of epigenetic population differentiation in a clonal invader. Frontiers of Plant Science, 9 , 1851. https://doi.org/10.3389/fpls.2018.01851

Smit, A. F. A., Hubley, R., \& Green, P. (2013-2015). RepeatMasker Open-4.0 2013-2015. https://www.repeatmasker.org/faq.html

Sousa, W. P., Kennedy, P. G., Mitchell, B. J., \& Ordóñez, L. B. M. (2007). Supply-side ecology in mangroves: Do propagule dispersal and seedling establishment explain forest structure? Ecological Monographs, 77, 53-76. https://doi.org/ 10.1890/05-1935

Spens, A. E., \& Douhovnikoff, V. (2016). Epigenetic variation within Phragmites australis among lineages, genotypes, and ramets. Biological Invasions, 18, 2457-2462. https://doi.org/10. 1007/s10530-016-1223-1

Sultan, S. E. (2015). Organism and environment: Ecological development, Niche construction, and adaptation. Oxford University Press. https://play.google.com/store/books/details? $\mathrm{id}=\mathrm{YG} 4 \mathrm{VDAAAQBAJ}$

Tomlinson, P. B. (2016). The botany of mangroves. Cambridge University Press. https://doi.org/10.1017/CBO9781139946575

Triest, L., Van der Stocken, T., De Ryck, D., Kochzius, M., Lorent, S., Ngeve, M., M., Ratsimbazafy, H. A., Sierens, T. van der Ven, R., \& Koedam, N. (2021). Expansion of the mangrove species Rhizophora mucronata in the Western Indian Ocean launched contrasting genetic patterns. Scientific Reports, 11, 4987. https://doi.org/10.1038/s41598-021-84304-8

Tumas, H. R., Shamblin, B. M., Woodrey, M. S., \& Nairn, C. J. (2019). Broad-scale patterns of genetic diversity and structure in a foundational salt marsh species black needlerush (Juncus roemerianus). Conservation Genetics, 20, 903-915. https://doi. org/10.1007/s10592-019-01183-3

van Gurp, T. P., Wagemaker, N. C. A. M., Wouters, B., Vergeer, P., Ouborg, J. N. J., \& Verhoeven, K. J. F. (2016). epiGBS: Reference-free reduced representation bisulfite sequencing. Nature Methods, 13, 322-324. https://doi.org/10.1038/nmeth. 3763 van Moorsel, S. J., Schmid, M. W., Wagemaker, N. C. A. M., van Gurp, T., Schmid, B., \& Vergeer, P. (2019). Evidence for rapid evolution in a grassland biodiversity experiment. Molecular Ecology, 28, 4097-4117. https://doi.org/10.1111/ mec.15191

Verhoeven, K. J. F., Jansen, J. J., Van Dijk, P. J., \& Biere, A. (2010). Stress-induced DNA methylation changes and their heritability in asexual dandelions. New Phytologist, 185, 1108-1118. https://doi.org/10.1111/j.1469-8137.2009.03121.x

Verhoeven, K. J. F., \& Preite, V. (2014). Epigenetic variation in asexually reproducing organisms. Evolution, 68, 644-655. https://doi.org/10.1111/evo.12320

Xie, H. J., Li, H., Liu, D., Dai, W. M., He, J. Y., Lin, S., Duan, H., Liu, L. L., Chen, S. G., Song, X. L., Valverde, B. E., \& Qiang, S. (2015). ICE1 demethylation drives the range expansion of a plant invader through cold tolerance divergence. Molecular Ecology, 24, 835-850. https://doi.org/10.1111/mec.13067

Zerebecki, R., Sotka, E. E., Hanley, T. C., Bell, K. L., Gehring, C., Nice, C. C., Richards, C. L., \& Hughes, A. R. (2021). Repeated genetic and adaptive phenotypic divergence across tidal elevation in a foundation plant species. The American Naturalist. http://dx.doi.org/10.1086/716512

Zhang, Y.-Y., Latzel, V., Fischer, M., \& Bossdorf, O. (2018). Understanding the evolutionary potential of epigenetic variation: A comparison of heritable phenotypic variation in epiRILs, RILs, and natural ecotypes of Arabidopsis thaliana. Heredity (Edinb.), 121, 257-265. https://doi.org/10.1038/s41 437-018-0095-9

Zogli, P., \& Libault, M. (2017). Plant response to biotic stress: Is there a common epigenetic response during plant-pathogenic and symbiotic interactions? Plant Science, 263, 89-93. https:// doi.org/10.1016/j.plantsci.2017.07.008

\section{SUPPORTING INFORMATION}

Additional Supporting Information may be found online in the supporting information tab for this article.

How to cite this article: Mounger, J., Boquete, M. T., Schmid, M. W., Granado, R., Robertson, M. H., Voors, S. A., Langanke, K. L., Alvarez, M., Wagemaker, C. A. M., Schrey, A. W., Fox, G. A., Lewis, D. B., Lira, C. F., \& Richards, C. L. (2021). Inheritance of DNA methylation differences in the mangrove Rhizophora mangle. Evolution \& Development, e12388. https://doi.org/10.1111/ede.12388 